\title{
Electron-beam-induced current measurements of thin-film solar cells
}

\author{
Daniel Abou-Ras ${ }^{1}$ and Thomas Kirchartz ${ }^{2,3}$ \\ ${ }^{1}$ Helmholtz-Zentrum Berlin für Materialien und Energie GmbH, Hahn-Meitner-Platz 1, 14109 Berlin, \\ Germany \\ ${ }^{2}$ IEK5-Photovoltaik, Forschungszentrum Jülich, 52425 Jülich, Germany \\ ${ }^{3}$ Faculty of Engineering and CENIDE, University of Duisburg-Essen, Carl-Benz-Str. 199, 47057 \\ Duisburg, Germany
}

Corresponding author: daniel.abou-ras@helmholtz-berlin.de

Keywords: Electron-beam-induced current, thin-film solar cells, scanning electron microscopy, tutorial review.

\begin{abstract}
:
The present tutorial review provides a practical guide to the analysis of semiconductor devices using electron-beam-induced currents (EBIC). The authors focus on cross-sectional EBIC measurements that provide an experimental assay of the efficiency of charge carrier collection in a semiconductor diode. The tutorial covers the fundamental physics of the technique, specimen preparation, data acquisition and numerical simulation and analysis of the experimental data. A key focus is put on application cases from the field of thin-film photovoltaics as well as specific pitfalls that may occur, such as effects occurring in high level injection and at grain boundaries of polycrystalline materials.
\end{abstract}

\section{Introduction}

In the research field of semiconductor devices, electron-beam-induced current (EBIC) measurements are an indispensable means of probing electrical properties of materials and of junctions in various semiconductor devices on the submicrometer scale. EBIC is a fairly old discipline going back to the work on the "electron voltaic effect" introduced by Ehrenberg et al. ${ }^{1}$ and Rappaport ${ }^{2}$ in the 1950s. Its usefulness is related to the fact that this technique is generally available at a scanning electron microscope, where imaging of the specimen can be combined with the laterally and depth-resolved measurements of the electron-beam-induced current as was first presented by Everhart et al. in $1963^{3}$. Thus, the combination of scanning electron microscopy (SEM) and EBIC is an appropriate tool to image device structures and study charge-carrier collection in a semiconductor diode with high spatial resolution. This is useful especially when aiming at correlating the structure of materials and their electrical properties.

The principle of EBIC is based on the generation of electron-hole pairs by an impinging electron beam. If electrons and holes are not separated spatially, they will eventually recombine. Thus, to enable efficient charge separation and subsequently to measure an electron-beam induced current, selective contacts have to be realized. Selective contacts are typically realized either by the means of doping (such as in a $p-n$ junction), by using materials with different workfunctions (such as in Schottky junctions) or by using combinations of both principles (as often done in semiconductor heterojunctions). Following electron-beam induced generation of electron/hole pairs in a device with selective contacts, an electrical current caused by the separated charge carriers will be measured at the external contacts. 
While the principle is simple, the acquisition and especially the interpretation of EBIC data is often challenging. The authors will cover issues such as surface roughness, contacting of devices, and low-injection vs. high-injection conditions as potential pitfalls of EBIC analyses. Various reviews and book chapters have already been written on charge collection in the electron microscope, including the contribution by D. Holt ${ }^{4}$ or the overview article by H.J. Leamy ${ }^{5}$. In the present work, it is the intention of the authors to provide a practical guide to EBIC analysis of semiconductor devices, focusing on $p$ - $n$ junctions and $p$ - $i$ - $n$ device structures for thin-film photovoltaics. The present EBIC tutorial covers the fundamental aspects of the technique (Section 2), describes the measurement procedure and the modeling of EBIC data (Section 3), addresses EBIC signals across line and planar defects (Section 4), and finally discusses pitfalls of EBIC measurements (Section 5).

\section{Basics of the EBIC measurement}

In an EBIC measurement, an electron beam is used to generate electron-hole pairs. These electron hole pairs may generate a current if a charge-carrier selective device structure is used. Figure 1 shows a schematic of the simplest selective device geometry, i.e., a $p$ - $n$-junction. As indicated, electron-beam irradiation may be realized onto the $n$-type or $p$-type semiconductor (plan-view configurations) as well as onto the cross-section of the device (see Figure 1). Although EBIC analyses in plan-view configurations can also provide valuable information about lateral variations in charge-carrier collection behaviors in thin-film solar cells (see. e.g., Refs. ${ }^{6}$ and ${ }^{7}$ ), the authors will concentrate on cross-sectional EBIC measurements in the following, since the study of the collection behavior perpendicular to the substrate provides direct insight into features which have an impact on the current flow in the thin-film device.

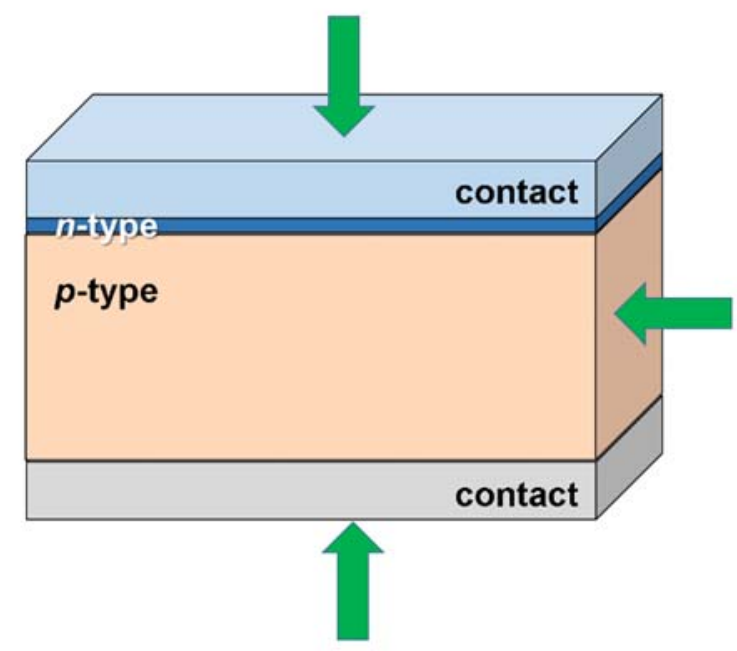

Figure 1: Schematics of a $p$ - $n$ junction with adjacent contacts. The arrows indicate the different possible configurations with the electron beam impinging either on the front or back contact, or on the cross-section of the layer stack.

Since the current IEBIC measured in an EBIC experiment is a result of subsequent carrier generation and collection, it can be described mathematically by the convolution of a generation profile $g(\vec{x}-\vec{a})$ and a collection probability $\varphi(\vec{x})$, which - reduced to one dimension - can be expressed in a general form as ${ }^{8}$

$$
\operatorname{IEBIC}(a)=\int_{-x_{\mathrm{fc}}}^{x_{\mathrm{bc}}} g(x-a) \varphi(x) d x
$$


where $a$ is the position of the incident electron beam on the specimen surface, $x$ is the position of the electron-hole generation and $x=-x_{\mathrm{fc}}$ and $x=x_{\mathrm{bc}}$ are the left and right edge of the part of the device where electron-hole pair generation is studied (see Figure 2). Note that we assume the generation profile $g(x)$ to have a finite extension around the position $a$ where the electron beam impinges on the surface. In a solar cell, the part of the electron-hole generation corresponds to the light-absorbing semiconductor layers but excludes metal contacts or transparent conductive oxides. In order to facilitate the evaluation and modeling of the EBIC data, homogeneous EBIC signals in the lateral directions will be assumed. The position coordinates $a$ and $x$ in Eq. 1 vary only in the direction perpendicular to the contacts.

The cross-sectional specimen of a thin-film solar cell depicted by the schematics in Figure 2 exhibits an asymmetric $p-n$ junction and a corresponding space-charge region (SCR). The positions along the $x$ axis of the front, $-x_{\mathrm{fc}}$, and back contacts, $x_{\mathrm{bc}}$, and the edge of the SCR, $x_{\mathrm{SCR}}$, as well as the recombination velocities at the back contact, $s \mathrm{bc}$, at the cross-section surface, $s \mathrm{SF}$, and at a grain boundary, $s \mathrm{~GB}$, are highlighted.

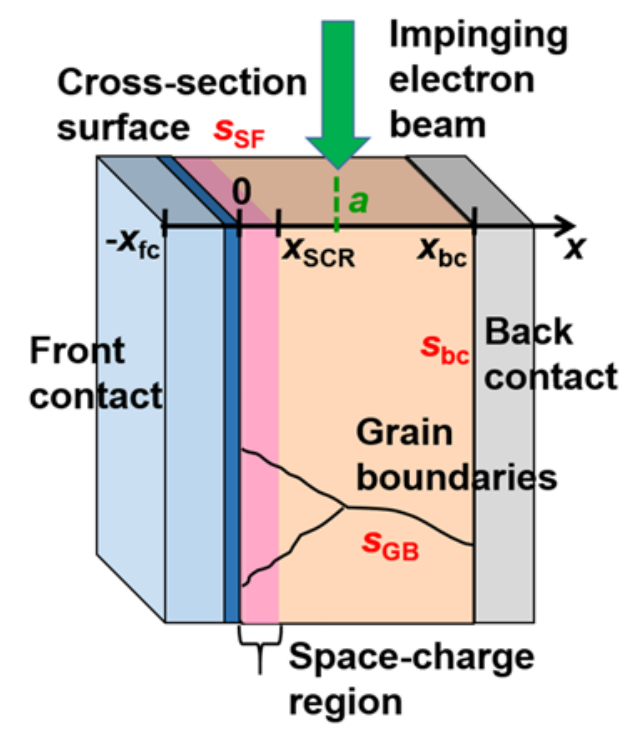

Figure 2: Schematic of a cross-section specimen of a thin-film solar cell with asymmetric $p-n$ junction, with relevant parameters for the present tutorial review. Given are the positions of the front, $-x_{\mathrm{fc}}$, and back contacts, $x_{\mathrm{bc}}$, the position of the impinging electron beam, $a$, and the edge of the SCR, $x_{\mathrm{SCR}}$, as well as the recombination velocities at the back contact, $s_{\mathrm{bc}}$, at the crosssection surface, $s_{\mathrm{SF}}$, and at a grain boundary, $s_{\mathrm{GB}}$.

In the course of the present work, we will describe in detail how to acquire EBIC images from cross-sectional specimens, from which EBIC profiles perpendicular to the $p$ - $n$ junction or to the selective contacts are extracted. Figure 3 a shows a schematic of the cross-section of a device with the $x$-axis going from the front to the back contact of a typical with a thin SCR and a thick quasi-neutral region (QNR). If somewhere in the QNR, an electron-hole pair is generated by an electron beam, the current will depend mostly on the probability that the minority carrier will diffuse to the SCR and is collected.

If we assume the QNR to be made up of a thick $p$-type layer as shown in the band diagram of Figure $3 \mathrm{~b}$, electrons will be the minority carriers. Thus, it will be the diffusion length $L_{\mathrm{n}}$ of electrons that controls the collection probability $\varphi$ shown in Figure $3 \mathrm{c}$. To a first approximation, the probability that an electron will be collected from a distance $\Delta x=x-x_{\mathrm{SCR}}$ away from the edge of the space charge region at $x=x_{\mathrm{SCR}}$ is given by $\exp \left(-\Delta x / L_{\mathrm{n}}\right)$. As indicated in Figure $3 \mathrm{c}$, 
higher diffusion lengths will lead to higher charge collection efficiencies and these will generally decay towards the back contact. This is due to the fact that at the back contact, the electrons have to diffuse the longest distance $\Delta x$ through the neutral layer. A more detailed mathematical analysis of the collection probability will follow in Sec. 3.2.

(a)
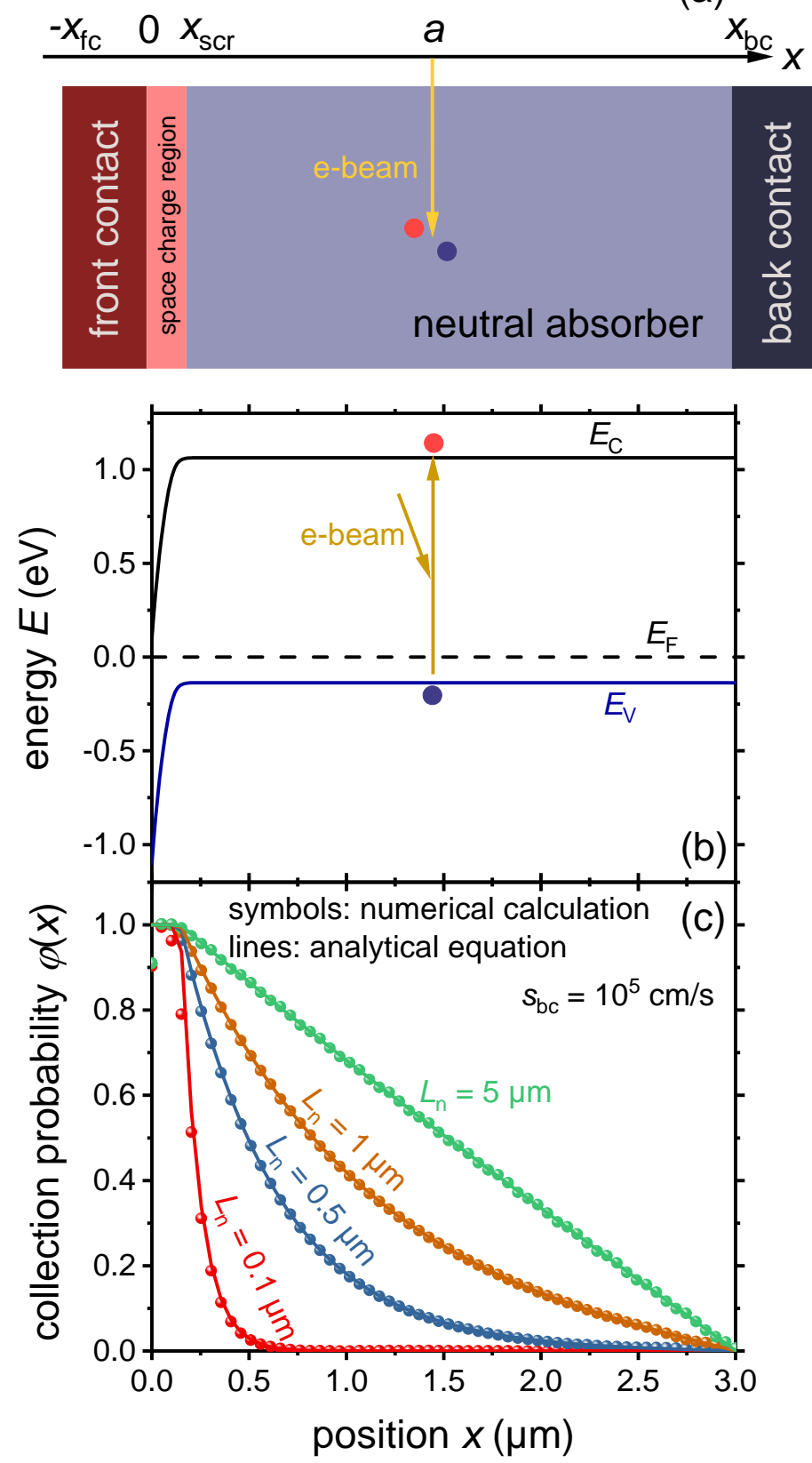

Figure 3: (a) Schematic of an asymmetric $p$ - $n$-junction with a thick neutral zone (blue) and a thin space charge region. (b) Band diagram of the same device. (c) Collection efficiency calculated numerically (symbols) compared to the analytical equation discussed in section 3.2 (lines). The bulk diffusion length $L_{\mathrm{n}}$ of minority carriers (electrons) is varied while the surface recombination velocity $S \mathrm{bc}=10^{5} \mathrm{~cm} / \mathrm{s}$ is kept constant.

\section{Conducting EBIC measurements}

\subsection{Practical aspects of EBIC analyses}




\subsubsection{Specimen preparation}

Optimizing the surface quality of a specimen before analysis in an electron microscope is essential in order to reduce possible measurement artifacts to a minimum. This principle is true also for EBIC measurements in a scanning electron microscope. Figure 4 shows an EBIC image acquired on a cross-sectional sample of a $\mathrm{Cu}(\mathrm{In}, \mathrm{Ga}) \mathrm{Se}_{2}$ thin-film solar cell, which was prepared simply by fracturing the device on a glass substrate. It is apparent that the cross-section exhibits a strong roughness, which has a substantial impact on the EBIC signal. From this EBIC data, it is not possible to conclude unambiguously whether features visible in the EBIC image are due to the roughness or due to material properties in the layer stack.
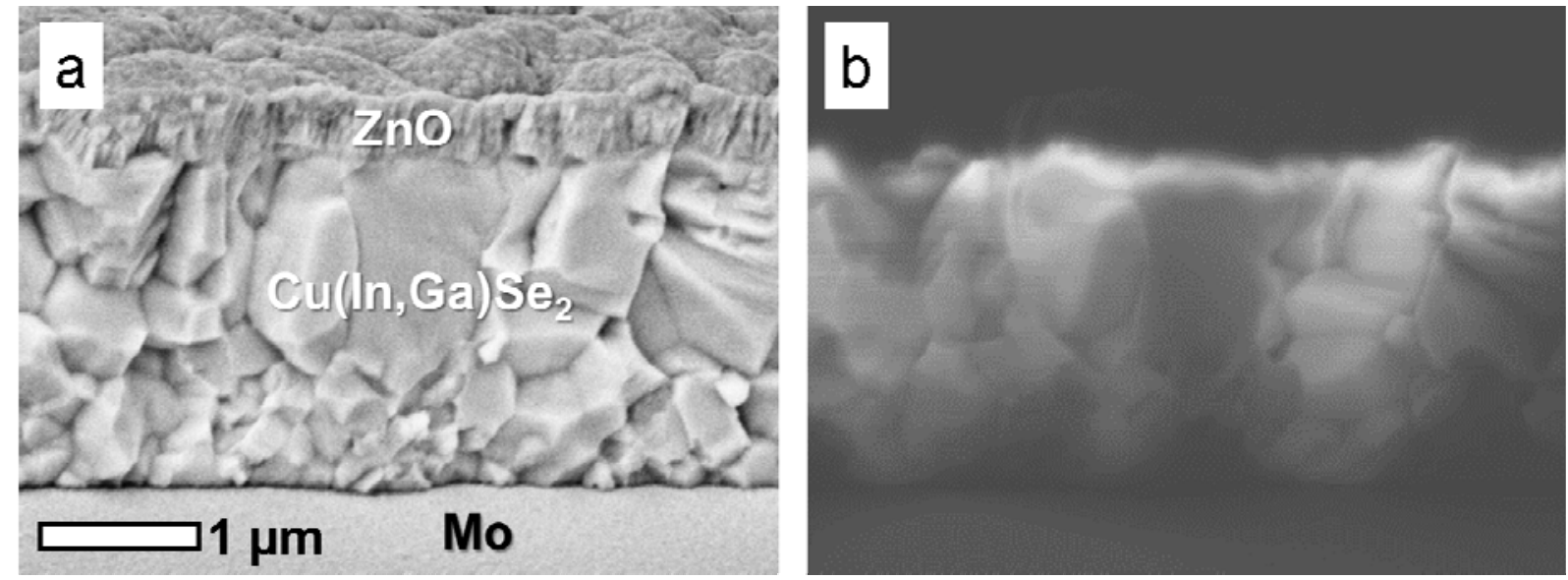

Figure 4: (a) SEM and (b) EBIC images, acquired on the identical position of a $\mathrm{ZnO} / \mathrm{CdS} / \mathrm{Cu}(\mathrm{In}, \mathrm{Ga}) \mathrm{Se}_{2} / \mathrm{Mo} /$ glass solar-cell stack (data courtesy by N. Schäfer, HZB).

The surface roughness can be reduced considerably by applying mechanical or ion-beam polishing of cross-sections. There are basically two different preparation recipes:

- Gluing two stripes of thin-film solar cells (substrate and the layer stack on top) face-toface together, then polishing of the cross-section mechanically (see Figure 5 for an illustration of the specimen). The resulting cross-section may be polished subsequently by an Ar-ion beam; however, at times, this additional process step may result in shunting of the devices, i.e., no EBIC signal can be measured.

- Direct slicing of a cross-section using a focused-ion beam (FIB) instrument; also for this preparation method, the ion bombardment may induce shunting paths in the devices, resulting in zero EBIC signals. In addition, a further possible artifact from FIB preparation concerns enhanced EBIC signals at grain boundaries, as compared with grain interiors (see Sec. 5.6).

For both approaches, the solar cell can be contacted in the same way as when acquiring currentvoltage characteristics, which may be (at times) more convenient than using nanoprobes (i.e., submicrometer-sized needles, which can be manipulated via piezoelectrical motors) in the scanning electron microscope. Also, when simply placing nanoprobes on two contact layers on the cross-sectional surface, it cannot be ruled out that the measured current actually does not flow through the device stack but across the surface of the specimen. 

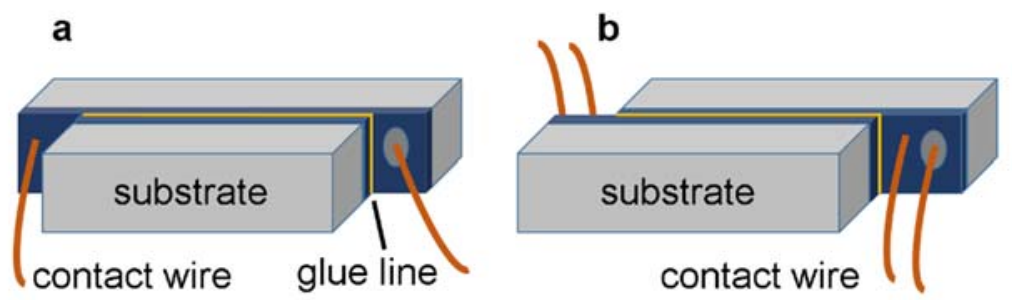

Figure 5: Different configurations for the specimen geometry used for cross-sectional EBIC analyses. Stacks are fabricated by face-to-face gluing of two thin-film solar cells on substrates, with the cross-section to be polished on the top surface. (a) Using only one of the solar cells for EBIC analysis. (b) By realigning the second solar cell, it is possible to contact both thin-film devices.

\subsubsection{An EBIC setup}

An experimental setup used for EBIC analyses is shown in Figure 6. A current can be collected at the contacts of a thin-film solar cell when scanning an electron beam across the cross-section of the device. An amplifier is needed which amplifies the EBIC signal (typically in the nA range), combined with a current-voltage converter, which results in a voltage signal on the order of $\mathrm{mV}$. This voltage signal can be used as input for a scanning electron microscope. Such a setup allows for acquiring scanning electron micrographs of the device in cross-section simultaneously to EBIC images, thus, providing the means to analyze the microscopic structureproperty relationships of the solar-cell stack.

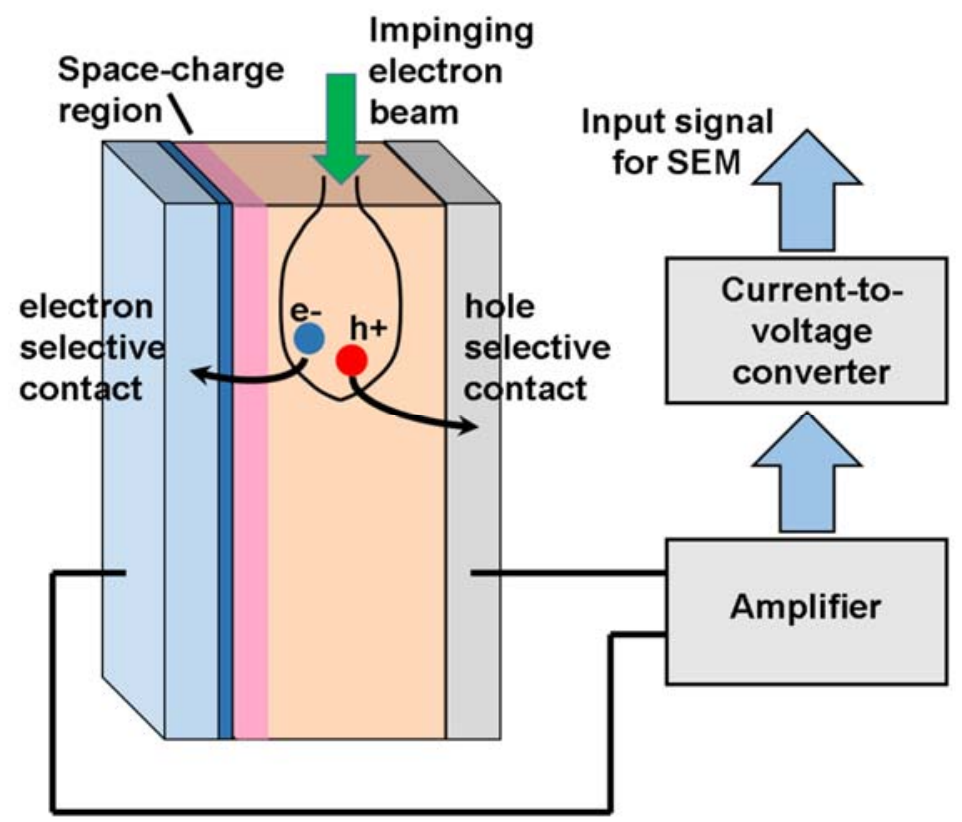

Figure 6: Experimental setup for EBIC analyses. The impinging electron beam in a scanning electron microscope generates electron-hole pairs, which are collected at the corresponding contacts. The resulting current, typically on the order of $\mathrm{nA}$ for an electron-beam current in the pA range, is amplified and converted into a voltage, which can be used as an input signal into the scanning electron microscope. Thus, scanning electron micrographs and EBIC images can be acquired simultaneously. 


\subsubsection{EBIC at varying bias voltages and the use of lock-in amplification}

In a standard EBIC measurement, the analysis is conducted at short circuit, and the acquired current density at the contacts can be regarded as the locally resolved short-circuit current density $\left(j_{\mathrm{sc}}\right)$ of the solar cell. However, in practice, a solar cell is not operated under short-circuit conditions but under illumination and forward bias, equivalent to the situation at the maximum power point of a solar cell. For instance, for a typical $\mathrm{Cu}(\mathrm{In}, \mathrm{Ga}) \mathrm{Se}_{2}$ solar cell, the voltage at the maximum power point is around $600 \mathrm{mV}$. Therefore, varying the working point of the device during EBIC analyses by changing bias voltages allows for studying the correspondingly changing collection behaviors (see, e.g., Ref. ${ }^{9}$ for an example). Such type of studies can be realized by using a beam blanker in the microscope column to chop the incident electron beam at a specific frequency (typically $1-10 \mathrm{kHz}$, order of magnitude) together with a synchronized lock-in amplifier. In general, lock-in amplification also results in a much better signal-to-noise ratio of the EBIC signal, thus, its use is always recommended if available.

\subsection{Analyses of $p-n$ junctions}

From an EBIC image acquired on a cross-section, a number of materials and device properties can be extracted. We shall consider $p-n^{+}$junctions in the present section, with a substantially higher doping in the $n$-type than in the $p$-type semiconductor. The principle idea is the following: The collection of charge carriers upon electron-beam irradiation is highest when the electron beam impinges into the SCR of the junction, since therein, an electrical field is present that separates effectively the generated electron-hole pairs. From the edges of the SCR, the EBIC signal decreases exponentially into the QNR of the absorber layer. This exponential decrease is closely related to the diffusion length of the minority carriers (electrons) in the absorber.

Figure 7 shows an SEM image and an EBIC image, both acquired on the identical position of a $\mathrm{ZnO} / \mathrm{CdS} / \mathrm{Cu}(\mathrm{In}, \mathrm{Ga}) \mathrm{Se}_{2} / \mathrm{Mo}$ solar-cell stack. In the EBIC image, a bright stripe is visible, which can be identified as the SCR of the solar cell. Before quantifying materials and device parameters from this measurement, linescans are extracted perpendicular to the substrate. 


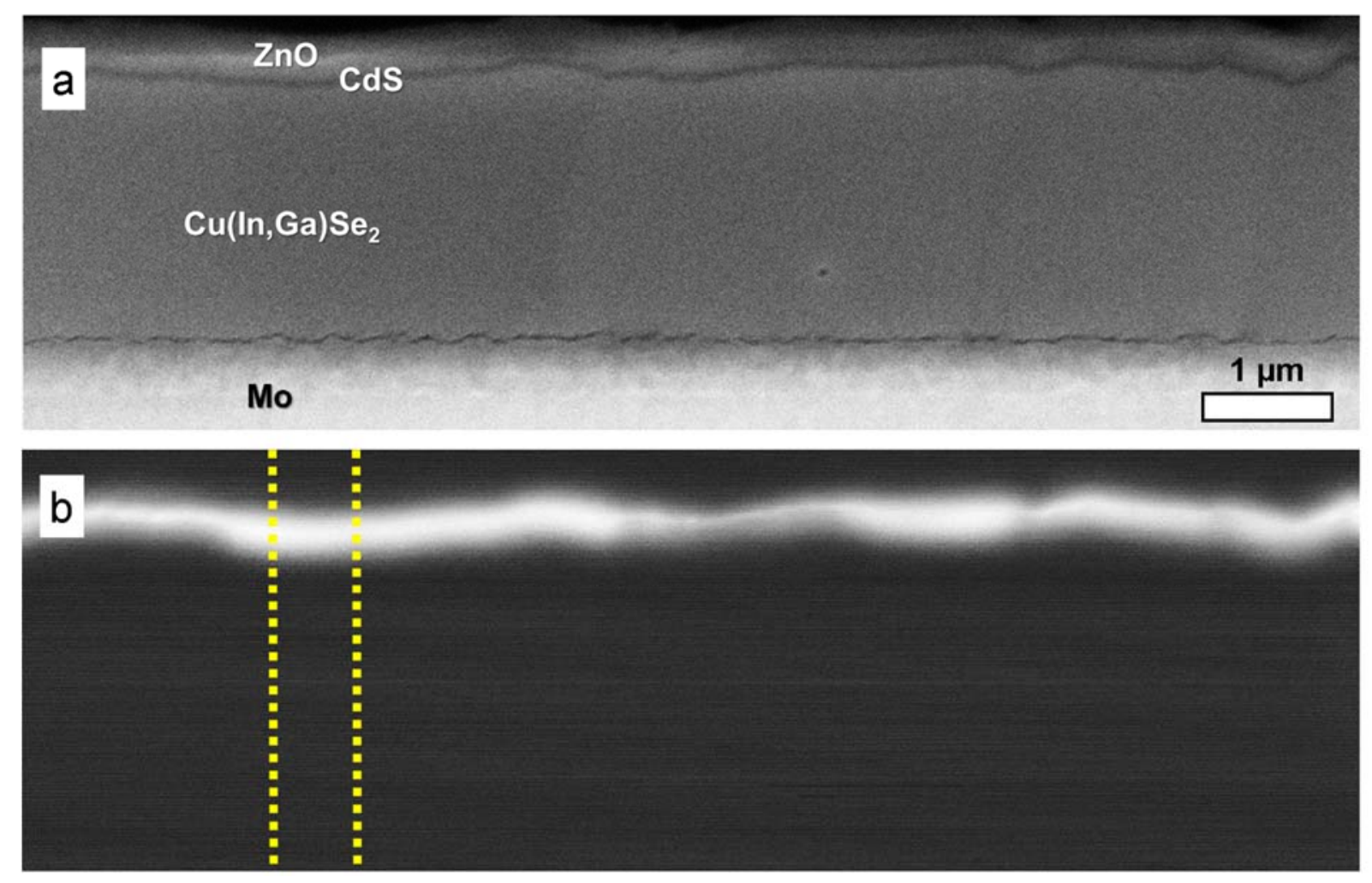

Figure 7: (a) SEM and (b) EBIC images, acquired on the identical position of a $\mathrm{ZnO} / \mathrm{CdS} / \mathrm{Cu}(\mathrm{In}, \mathrm{Ga}) \mathrm{Se}_{2} / \mathrm{Mo} /$ glass solar-cell stack (data by courtesy of M. Nichterwitz, HZB)

Figure 8 shows such a linescan (straight black line), extracted from the area highlighted by dotted lines in the EBIC image in Figure 7b. Apparently, the EBIC linescan exhibits a plateau (local maximum), and also, the signal on either side of this plateau decreases exponentially from the edges to the contacts. This plateau (bright stripe in Figure 7b) can be identified as the position of the SCR in the device. However, in order to determine the specific value of the width of the SCR, the measured EBIC profile needs to be simulated.

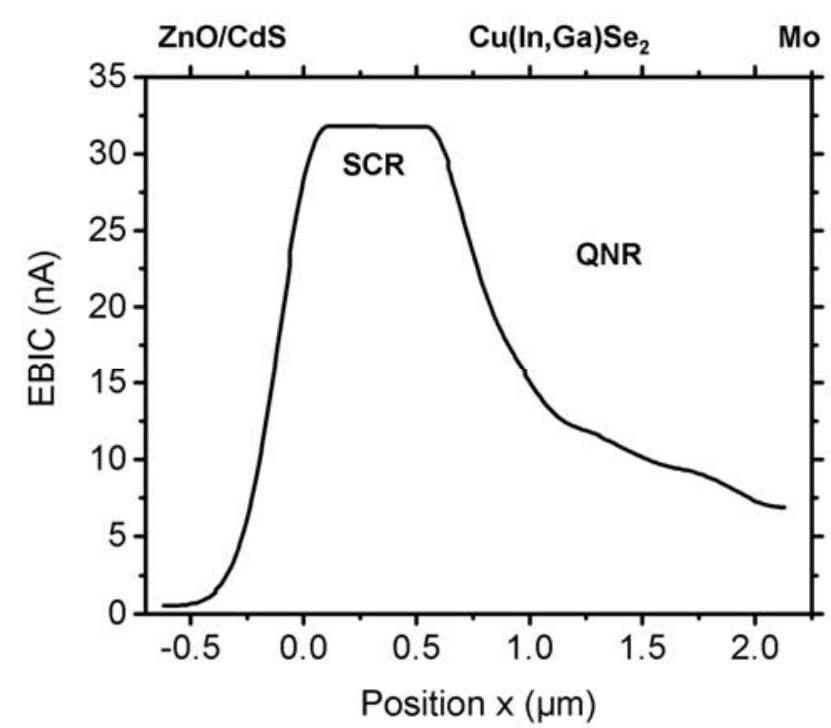

Figure 8: Averaged linescan extracted from the area in the EBIC image in Figure $7 \mathrm{~b}$ highlighted by two dotted lines. 
The analytical fitting routine used to simulate the EBIC profile in Figure 8 is based on a generation profile $g(x-a)$ and a collection probability $\varphi(x)$, which are convoluted according to Eq. 1 in order to result in the EBIC distribution perpendicular to the substrate.

\subsubsection{The generation profile}

The generation profile $g(x-a)$ can be approximated via ${ }^{10,11}$ :

$g(x-a)=3 A / R_{\mathrm{G}} \exp \left(-10.3(x-a)+29.7(x-a)^{2}-56.9(x-a)^{3}+44.8(x-a)^{4}-13.5(x-a)^{5}\right)$,

an empirical equation, in which $x$ is the position where the electron-hole pair was generated, $a$ is the position where the electron impinges on the specimen surface, $R_{\mathrm{G}}$ the Green penetration depth with

$$
R_{\mathrm{G}}=(0.043 / \rho) E_{\mathrm{b}}{ }^{1.75}
$$

( $\rho$ is the mass density of the semiconductor and $E_{\mathrm{b}}$ the beam energy), and the generation rate of electron-hole pairs per $\mathrm{cm}^{3}$ and $\mathrm{s}$,

$$
A=E_{\mathrm{b}} I_{\mathrm{b}}(1-\lambda) /\left(e E_{\mathrm{eh}}\right) .
$$

Here, $I_{\mathrm{b}}$ is the beam current, $e$ is the elemental charge, $E_{\mathrm{eh}}=2.1 E_{\mathrm{g}}+1.3$ is the effective energy for the formation of an electron-hole pair ( $E_{\mathrm{g}}$ is the band-gap energy of the semiconductor), and $\left.\lambda=\left(\alpha-1+(0.5)^{\alpha}\right) /(\alpha+1)\right)$ with $\alpha=0.045^{*} Z$ ( $Z$ is the atomic number).

\subsubsection{The collection probability}

In Figure 3c, we introduced the collection probability $\varphi(x)$, which defines the probability that an electron-hole pair generated at position $x$ contributes one elementary charge to the steadystate current flowing out of the device. The collection probability can be calculated numerically using a drift-diffusion simulator where charges are generated at different positions $x$ within the device, and then the current flowing in short circuit is calculated by numerically solving the continuity equations for electrons and holes as well as the Poisson equation relating the electric charge density to the electrostatic potential. For a review of drift-diffusion simulations the reader is referred to, e.g., Ref. ${ }^{12}$.

The symbols in Figure 3c are calculated using drift-diffusion simulations performed using the software $\mathrm{ASA}^{13}$. In addition to purely numerical simulations, there are analytical solutions to the collection efficiency for the neutral zone of a $p-n$ junction or Schottky junction type device. These analytical solutions are based on the idea that in certain situations, from the three coupled differential equations (continuity equations for electrons and holes as well as the Poisson equation) only one remains relevant. In the neutral zone in low-level injection (i.e., the concentration of excess charge carriers is smaller than the doping density), the electric field is zero, i.e., there is no need to calculate the electrostatic potential using Poisson's equation. In addition, also the continuity equation for the majority carriers becomes irrelevant because their concentration will be set equal to the concentration of ionized dopants that we assume to be constant over the neutral zone for simplicity. In this case, only the continuity equation for minority carriers remains and reads for a $p$-type semiconductor

$$
D_{\mathrm{n}} \frac{d \Delta n^{2}}{d x^{2}}-\frac{\Delta n}{\tau}=0 \text {. }
$$


Eq. 4 assumes that there is no external generation of charge carriers by an electron beam or by photons. Here $D_{\mathrm{n}}$ is the diffusion constant of electrons, $\Delta n$ is the excess electron concentration and $\tau$ is the bulk lifetime. In the following, we will first solve Eq. 4 in order to obtain the concentration of charge carriers in the dark, before we determine the collection efficiency under illumination with an electron beam. Solving Eq. 4 requires boundary conditions at the front and back contact. At the front contact, we will set the concentration of electrons to a fixed value that is in practice given by the applied voltage. At the back contact at $x=x$ bc we use the boundary condition

$$
\left.S_{\mathrm{bc}} \Delta n\right|_{x=x_{\mathrm{bc}}}=-\left.D_{\mathrm{n}} \frac{d \Delta n(x)}{d x}\right|_{x=x_{\mathrm{bc}}} .
$$

Solving the differential equation (Eq. 4) with the boundary conditions detailed above leads to

$$
\frac{\Delta n_{\mathrm{d}}(x)}{\Delta n_{\mathrm{d}}\left(x_{\mathrm{SCR}}\right)}=\cosh \left(\frac{x-x_{\mathrm{SCR}}}{L_{\mathrm{n}}}\right)-\frac{L_{\mathrm{n}}}{L_{\mathrm{eff}}} \sinh \left(\frac{x-x_{\mathrm{SCR}}}{L_{\mathrm{n}}}\right),
$$

where $x=x_{\mathrm{SCR}}$ specifies the edge of the SCR and the beginning of the neutral base. The thickness of the base is denoted as $w=x_{\mathrm{bc}}-x_{\mathrm{SCR}}$. Here, we used the electron diffusion length $L_{\mathrm{n}}=\sqrt{D_{\mathrm{n}} \tau}$ and the so-called effective diffusion length $L_{\text {eff }}$ defined via ${ }^{14}$

$$
L_{\mathrm{eff}}=L_{\mathrm{n}} \frac{s_{\mathrm{bc}} \sinh \left(\frac{w}{L_{\mathrm{n}}}\right)+\frac{D_{\mathrm{n}}}{L_{\mathrm{n}}} \cosh \left(\frac{w}{L_{\mathrm{n}}}\right)}{s_{\mathrm{bc}} \cosh \left(\frac{w}{L_{\mathrm{n}}}\right)+\frac{D_{\mathrm{n}}}{L_{\mathrm{n}}} \sinh \left(\frac{w}{L_{\mathrm{n}}}\right)} .
$$

The effective diffusion length depends both, on bulk lifetime $\tau$ and back surface recombination velocity $S$ bc.

The solution of the diffusion equation in the dark initially seems of little relevance for the situation encountered during an EBIC experiment. The solution in the dark is valid for any applied voltage but always only in the case without external generation. However, the two situations are closely related to each other. Eq. 6 describes minority carrier injection into a neutral zone of a $p$ - $n$ junction while the collection efficiency describes the process of charge extraction from a certain point within the neutral zone. These processes are connected by detailed balance ${ }^{15}$ and therefore they have to be related by a reciprocity relation that mathematically describes the relation between charge injection into and extraction from a neutral zone with recombination terms linear in excess charge carrier concentration (i.e. with a constant $\tau$ and $s$ bc). The reciprocity theorem for charge collection and extraction was formulated initially by Donolato ${ }^{16}$ and several different derivations, generalizations and further applications where later formulated by additional authors $8,15,17,18,19,20,21$. The theorem states that the collection efficiency $\varphi(x)$ has the same spatial dependence as the normalized minority carrier density in the dark, i.e.

$$
\varphi(x)=\frac{\Delta n_{\mathrm{d}}(x)}{\Delta n_{\mathrm{d}}\left(x_{\mathrm{SCR}}\right)}=\cosh \left(\frac{x-x_{\mathrm{SCR}}}{L_{\mathrm{n}}}\right)-\frac{L_{\mathrm{n}}}{L_{\mathrm{eff}}} \sinh \left(\frac{x-x_{\mathrm{SCR}}}{L_{\mathrm{n}}}\right) .
$$

Now it becomes clear why the solution of the diffusion equation in the dark already solves the problem of the collection efficiency under illumination with an electron beam (or with light). Combined with Donolato's theorem ${ }^{16}$, Eq. 6 already provides an analytical equation (solid lines in Figure 3c) for $\varphi(x)$ that fits well to the numerical solutions (symbols) as shown in Figure 3c. Eq. 8a can also be expressed in the following form: 


$$
\varphi(x)=\frac{\frac{1}{L_{\mathrm{n}}} \cosh \left(\frac{x-x_{\mathrm{bc}}}{L_{\mathrm{n}}}\right)-\frac{s_{\mathrm{bc}}}{D_{\mathrm{n}}} \sinh \left(\frac{x-x_{\mathrm{bc}}}{L_{\mathrm{n}}}\right)}{\frac{s_{\mathrm{bc}}}{D_{\mathrm{n}}} \sinh \left(\frac{x_{\mathrm{bc}}-x_{\mathrm{SCR}}}{L_{\mathrm{n}}}\right)-\frac{1}{L_{\mathrm{n}}} \cosh \left(\frac{x_{\mathrm{bc}}-x_{\mathrm{SCR}}}{L_{\mathrm{n}}}\right)} .
$$

For the simulation of the EBIC profile acquired across a $p$ - $n$ junction, it is convenient to divide the junction into three regions (see Figs. 8 and $9 \mathrm{~b}$ below):

- The larger neutral region (QNR on the right in Figure 8). The collection probability follows from Eq. (8b) as shown above.

- The smaller neutral region (on the left in Figure 8, for $-x_{\mathrm{fc}}<x<0$, with $-x_{\mathrm{fc}}$ the position of the front contact). These smaller neutral regions in some common thin-film solar cell devices such as those based on $p$-type $\mathrm{Cu}(\mathrm{In}, \mathrm{Ga}) \mathrm{Se}_{2}$ and $\mathrm{CdTe}$ absorbers are due to the much higher doping densities in the $n$-type counterparts (which is $\mathrm{ZnO} / \mathrm{CdS}$ in Figure 8 ) and therefore exhibit very low minority-carrier diffusion lengths $L_{\mathrm{p}}$. For the example that the region on the left is $n$-type (as in Figure 8), the collection probability may still be calculated with a modified version of Eq. (8) that reads

$$
\varphi(x)=\frac{\Delta p_{\mathrm{d}}(x)}{\Delta p_{\mathrm{d}}(0)}=\cosh \left(\frac{-x}{L_{\mathrm{p}}}\right)-\frac{L_{\mathrm{p}}}{L_{\text {eff }}^{\mathrm{n} \text {-type }}} \sinh \left(\frac{-x}{L_{\mathrm{p}}}\right)
$$

with the effective diffusion length for the neutral n-type region being defined as

$$
L_{\text {eff }}^{n-\text { type }}=L_{\mathrm{p}} \frac{s_{\mathrm{fc}} \sinh \left(\frac{x_{\mathrm{fc}}}{L_{\mathrm{p}}}\right)+\frac{D_{\mathrm{p}}}{L_{\mathrm{p}}} \cosh \left(\frac{x_{\mathrm{fc}}}{L_{\mathrm{p}}}\right)}{s_{\mathrm{fc}} \cosh \left(\frac{x_{\mathrm{fc}}}{L_{\mathrm{p}}}\right)+\frac{D_{\mathrm{p}}}{L_{\mathrm{p}}} \sinh \left(\frac{x_{\mathrm{fc}}}{L_{\mathrm{p}}}\right)}
$$

However, often, the condition $L_{\mathrm{p}}<<x_{\mathrm{fc}}$ is fulfilled, in which case the collection efficiency simplifies to

$$
\varphi(x)=\exp \left(x / L_{\mathrm{p}}\right)
$$

- The SCR: In the SCR, it is more difficult to find analytical solutions for the spatial dependence of the collection efficiency. All practical $p$ - $n$ junctions are asymmetric $p-n$ junctions implying that there is one region whose doping is much lower than the other. The SCR will primarily extend into the region with the lower doping density, which, for a solar cell, is the main absorber region with the (hopefully) higher diffusion length than the thin, highly doped buffer layer. Because (i) the SCR is often much smaller in thickness than the larger of the neutral regions and because (ii) the electric field increases the probability of charge collection, it is therefore usually reasonable to assume $\varphi=1$ for all $x$ within the SCR (ranging from $x=0$ to $x=x_{\mathrm{SCR}}$ ). Consequently, the width of the SCR, $x_{\mathrm{SCR}}$, is one of the dominant simulation parameters to fit the experimentally determined EBIC profile.

An exemplary generation profile $g(x-a)$ and a collection probability $\varphi(x)$ are given in Figure 9a and b, which were calculated using Eqs. 2, 8b, and 11 as well as the parameters summarized in Table 1. Figure 9c shows the resulting, simulated EBIC profile, together with the experimental EBIC profile from Figure 8. 
Table 1. Parameters for the calculation of the generation profile $g(x-a)$ and the collection probability $\varphi(x)$ using Eqs. 2, 8b, and 11.

\begin{tabular}{ll}
\hline Parameter & Value \\
\hline$E_{\mathrm{b}}(\mathrm{keV})$ & 8 \\
\hline$I_{\mathrm{b}}(\mathrm{pA})$ & 10 \\
\hline$E_{\mathrm{g}}(\mathrm{eV})$ & 1.15 \\
\hline$Z$ & 35 \\
\hline$\rho\left(\mathrm{g} / \mathrm{cm}^{3}\right)$ & 5.75 \\
\hline$L_{\mathrm{e}}(\mathrm{nm})$ & 500 \\
\hline$L_{\mathrm{h}}(\mathrm{nm})$ & 150 \\
\hline$w_{\mathrm{SCR}}=x_{\mathrm{SCR}}(\mathrm{nm})$ & 600 \\
\hline$D_{\mathrm{e}}(\mathrm{cm} / \mathrm{s})$ & 3 \\
\hline$S_{\mathrm{bc}}(\mathrm{cm} / \mathrm{s})$ & $8 \times 10^{4}$ \\
\hline$x_{\mathrm{fc}}(\mu \mathrm{m})$ & 0.5 \\
\hline$x_{\mathrm{bc}}(\mu \mathrm{m})$ & 3 \\
\hline
\end{tabular}



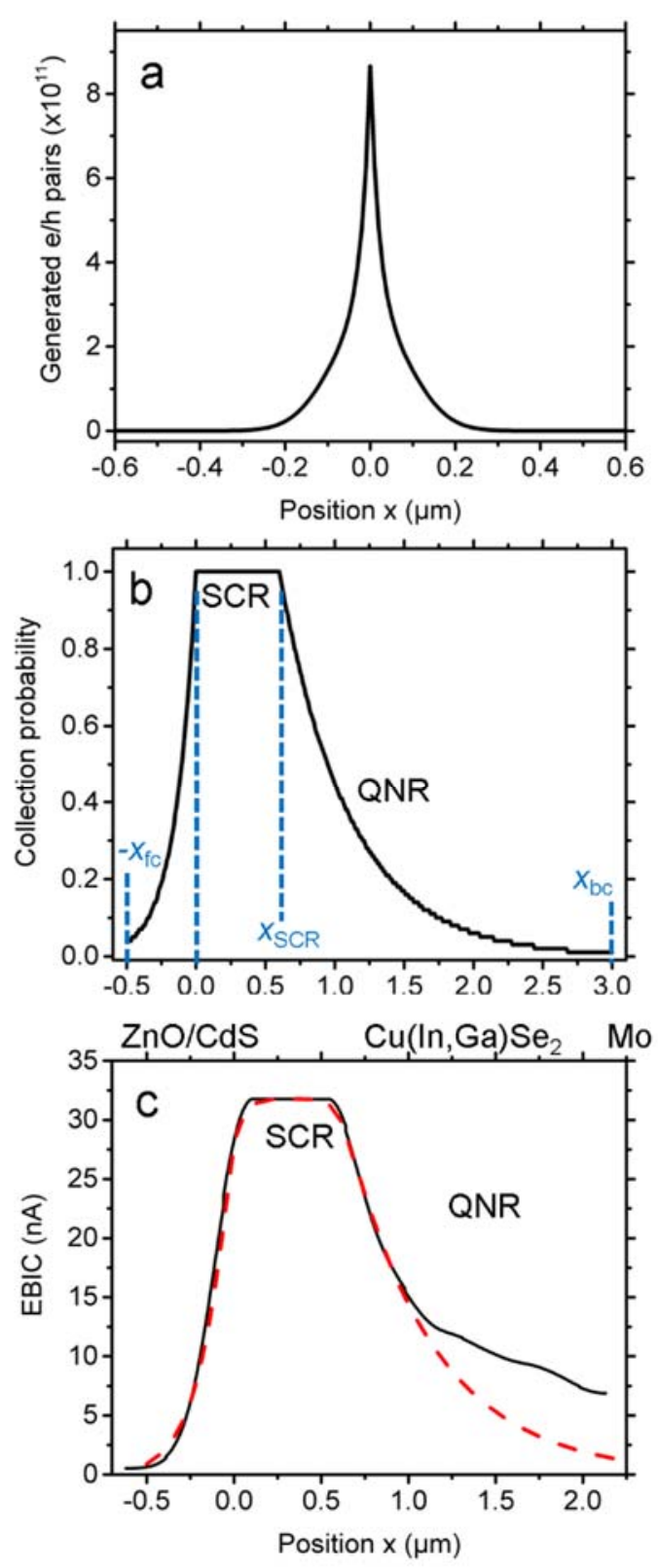

Figure 9: Generation profile $g(x)$ (a) and the collection probability $\varphi(x)$ (b) calculated using Eqs. 2, 8b, and 11 as well as the parameters detailed in Table 1. (c) Averaged linescan depicted in Figure 8 (straight black line), as well as the corresponding simulation (dashed red line). Note that this simulation is the result of the convolution of the generation profile $g(x-a)$ and the collection probability $\varphi(x)$ (according to Eq. 1), which are depicted in (a) and (b). The deviation of the simulated to the experimental EBIC profile in the QNR can be attributed to a channeling effect (see Sec. 5.2).

The electron diffusion lengths $L_{\mathrm{n}}$ and $L_{\mathrm{p}}$ as well as the width of the SCR are important materials and device parameters that are related to the electron lifetime $\tau_{\mathrm{n}}$ and to the netdoping densities $N_{\mathrm{A}}$ and $N_{\mathrm{D}}$ of the $n$-type and $p$-type sides of the junction ${ }^{22}$. While the width of the SCR has been shown to agree well with corresponding values obtained by capacitancevoltage measurements ${ }^{9}$, the electron diffusion lengths $L_{\mathrm{n}}$ determined from EBIC analyses are influenced strongly by the recombination of charge carriers at the cross-section surface, i.e., the measured values are substantially smaller than the real electron diffusion lengths $L_{\mathrm{n}}$. A 
method to correct for the surface recombination is shown in the following subsection; still, even the corrected values are often smaller than values obtained by photoluminescence ${ }^{23}$ (i.e., by determining the lifetime $\tau_{\mathrm{n}}{ }^{24}$ and then calculating $L_{\mathrm{n}}=\left(D_{\mathrm{n}} \tau_{\mathrm{n}}\right)^{0.5}$ using an appropriate electron diffusion constant $D_{\mathrm{n}}$ ). We note that also quantum efficiency measurements ${ }^{25}$ on complete devices are a reliable way to determine electron diffusion length in the solar absorber.

\subsubsection{Influence of recombination at the cross-section surface}

Taking into account the recombination at the front $\left(s_{\mathrm{fc}}\right)$ and back contacts $(\mathrm{s} \mathrm{bc})$ of the solar cell (i.e., at $-x_{\mathrm{fc}}$ and $x_{\mathrm{bc}}$ in Figure 2) has led to the concept of the effective diffusion length (see Eqs. 7 and 10) to combine the effects of recombination in the bulk and at these interfaces towards the contact materials. However, while for quantum efficiency or photoluminescence measurements of solar cells, the lateral dimension can be assumed to be extended infinitely, in the specific case of EBIC measurements performed on cross-sections, also one additional surface perpendicular to the absorber-contact interfaces becomes relevant. Figure 10 shows a schematic of a sample for EBIC measurements indicating the surface recombination velocities at the back contact, $S \mathrm{bc}$ (as discussed in the context of the effective diffusion length in Eq. 7), and a recombination velocity at the cross-sectional surface, $s \mathrm{SF}$. We neglect $s \mathrm{fc}$ in the following, since $L_{\mathrm{p}}<<x_{\mathrm{fc}}$.

Indeed, the effective electron diffusion length $L_{\mathrm{eff}}$ (Eq. 7) is a function of the beam energy $E_{\mathrm{b}}$, and the influence of the surface recombination $s \mathrm{SF}$ on $L_{\mathrm{eff}}$ is larger the smaller $E_{\mathrm{b}}$ is. In order to estimate the reduced electron-diffusion length at the cross-section surface, $L_{\mathrm{s}}$, from $L_{\mathrm{eff}}\left(E_{\mathrm{b}}\right)$ values determined at various $E_{\mathrm{b}}$, the influence of the surface-recombination velocity $s_{\mathrm{SF}}$ is considered using an expression proposed by Jastrzebski et al. ${ }^{26}$ and Donolato ${ }^{27}$ :

$$
L_{\mathrm{s}}^{2}\left(z, s_{\mathrm{SF}}\right)=L_{\mathrm{eff}}^{2}\left[1-\left(s_{\mathrm{SF}} L_{\mathrm{eff}} / D_{\mathrm{n}}\right) /\left(1+s_{\mathrm{SF}} L_{\mathrm{eff}} / D_{\mathrm{n}}\right) \exp \left(-z / L_{\mathrm{eff}}\right)\right]
$$

This dependence on the electron-beam energy $E_{\mathrm{b}}$ requires the introduction of a new coordinate, $\mathrm{z}$, perpendicular to the cross-section surface (see Figure 10). This is, we are dealing with a twodimensional problem, where the EBIC value in QNR of the absorber layer can be written as $I_{E B I C}^{Q N R}=\int_{-x_{\mathrm{fc}}}^{x_{\mathrm{bc}}} \mathrm{d} x \int_{0}^{R_{G}} \mathrm{~d} z g(x, z) \varphi(x, z)$, corresponding to Eq. 1. Kniese ${ }^{28}$ proposed an approach to separate the dependencies on $x$ and $z$ coordinates, via averaging of the $x$-dependencies of $g(x, z)$ and $\varphi(x, z)$ each over the $z$ coordinate. The result is an average, effective diffusion length $L_{\mathrm{eff}, \text { surf }}\left(E_{\mathrm{b}, S \mathrm{SF}}\right)$, which can be expressed as

$$
L_{\mathrm{eff}, \mathrm{surf}}^{2}\left(E_{\mathrm{b}}, s_{\mathrm{SF}}\right)=\int_{0}^{\infty} \mathrm{d} z \hat{g}_{x}\left(z, E_{\mathrm{b}}\right) L_{\mathrm{s}}^{2}\left(z, s_{\mathrm{SF}}\right)
$$

introducing a normalized generation profile ${ }^{29}$

$$
\hat{g}_{x}\left(z, E_{\mathrm{b}}\right)=1 / A g(z)=1 / R_{\mathrm{G}}\left[0.6+6.21\left(z / R_{\mathrm{G}}\right)-12.4\left(z / R_{\mathrm{G}}\right)^{2}+5.69\left(z / R_{\mathrm{G}}\right)^{3}\right] \text {. }
$$

The combination of Eqs. 12 and 13 results in the following expression for the average, effective diffusion length including the effect of the cross-section surface:

$$
L_{\text {eff,surf }}^{2}\left(E_{\mathrm{b}}, s_{\mathrm{SF}}\right)=L_{\mathrm{eff}}^{2}\left[1-\frac{s_{\mathrm{SF}} L_{\mathrm{eff}} / D_{\mathrm{n}}}{\left(1+s_{\mathrm{SF}} L_{\mathrm{eff}} / D_{\mathrm{n}}\right)}\right] \int_{0}^{\infty} \mathrm{d} z \hat{g}_{x}\left(z, E_{\mathrm{b}}\right) \exp \left(-z / L_{\mathrm{eff}}\right),
$$

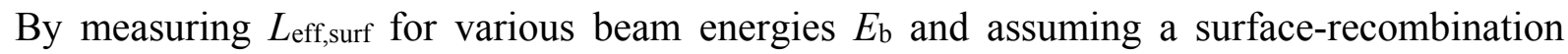
velocity $s \mathrm{SF}, L$ eff can be determined. Typical values for $s$ SF in experiments on CIGS-based solar 
cells range between about $10^{4}$ and $10^{6} \mathrm{~cm} / \mathrm{s}$ (e.g., Refs. ${ }^{30,43}$ ), reducing $L$ eff by up to one order of magnitude.

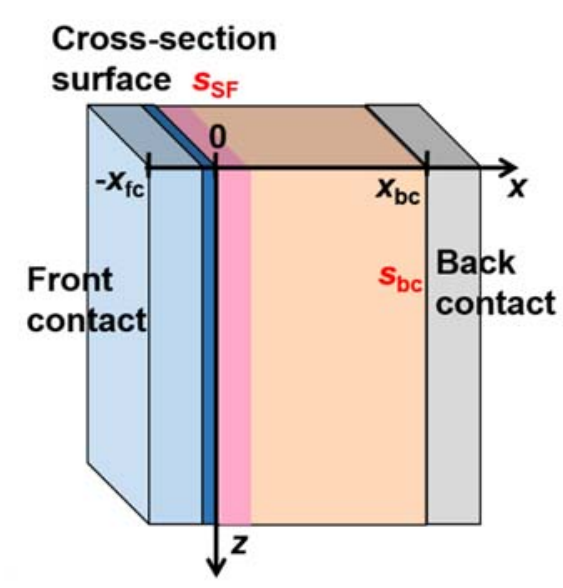

Figure 10: Schematics of a thin-film solar-cell stack, highlighting the recombination velocities $s \mathrm{SF}$ and $s$ bc at the cross-section surface and at the absorber/back contact interface, as well as coordinates $x$ and $z$.

\subsection{Analyses of $p-i-n$ structures}

The collection probability of an asymmetric $p$ - $n$ junction as shown in Figure $3 \mathrm{c}$ can be calculated analytically (outlined in Sec. 3.2.2). The key for these equations to be applicable is the condition of low-level injection, i.e., that one carrier is present in excess of the other carrier throughout the whole range of used electron beam fluences. This condition requires the doping density in the neutral zone in Figure $3 b$ to be higher than the excess charge-carrier density created by the electron beam. If the doping is too low, the e-beam generated electron and hole density will dominate the total density of charge carriers either throughout the whole device or at least throughout a substantial part of the device (more than the thin space charge region indicated in Figures 3a and b). In this situation, called high-level injection, the Donolato theory is no longer applicable, and especially, Eq. 6 becomes invalid. Figure 11 shows an exemplary situation of high level injection in a $p$ - $i$ - $n$-type device with a thick intrinsic layer sandwiched between two infinitely thin layers with different workfunctions. Figure 11a shows the band diagram of the intrinsic layer only at $0 \mathrm{~V}$ applied bias in the dark.

Charge collection in such a device is controlled by the drift length $L \mathrm{dr}=\mu \tau F$, where $F$ is the electric field ${ }^{31,32,33}$. As in the case of the diffusion length, the drift length can be defined for electrons or for holes. If we assume both, mobility and lifetime, to be the same for electrons and holes, the collection efficiency will be highly symmetric as shown in Figure $11 \mathrm{~b}$ (symbols). The collection efficiency will be highest in the middle of the intrinsic layer where electrons and holes have the same distance towards their corresponding, collecting electrode. Any shift relative to the middle of the layer will increase the path for either electrons or holes and will decrease the collection probability. The collection efficiency will decay from the middle roughly by $\exp \left(-\Delta x / L_{\mathrm{dr}}\right.$ ), where $\Delta x$ is the distance from the middle of the intrinsic layer (solid lines in Figure 11b).

If we abandon the condition of equal properties for electrons and holes, the situation in Figure 11c will result. Now holes are less mobile than electrons and the point of highest collection efficiency will move towards the hole contact and the decay will become asymmetric. Note that in steady state, the slower extraction of holes will lead to hole accumulation inside 
the absorber layer which will then accelerate the extraction of holes (the slower carrier) by the formation of an electric field close to the anode and slow down the extraction of electrons by reducing the electric field towards the cathode ${ }^{34}$. One can imagine that in the limit of one mobility going towards infinite (and the other mobility being finite), the peak of the collection efficiency will approach the contact of the faster carrier. Then, the spatial dependence of the collection efficiency would approach the shape shown before for the cases of low level injection (see e.g. Figure 3c).

Figure 12 shows experimental data of solar cells with absorber layers that have a low doping concentration (on the order of $10^{14} \mathrm{~cm}^{-3}$ ). This implies that, in an EBIC measurement, the absorber is exposed to high-level injection. Based on the simulations in Figure 11, we would expect a single peak that is symmetric or asymmetric, depending on whether the efficiencies of charge extraction for electrons and holes are similar or different. Figure 12a shows the EBIC profile across a CdS/CdTe solar cell (CdS on the left, CdTe on the right). Here, the shape of the EBIC signal is quite symmetric in the CdTe layer and negligibly low in the CdS layer. Thus, this situation is similar to the simulations shown in Figure $11 \mathrm{~b}$ for drift lengths substantially lower than the absorber thickness.

Figure $12 \mathrm{~b}$ shows the EBIC profiles extracted across two methylammonium-lead-iodide (MAPI) based solar cells. In both cases, the device structure used is based on an $\mathrm{FTO} / \mathrm{TiO}_{2}$ cathode and a Au anode. In Figure 12b, the hole contact (anode) is on left, and the electron contact (cathode) is on the right. Illumination in a solar cell is possible through the transparent cathode. The EBIC scan shown in blue was acquired across a $\mathrm{Au} / \mathrm{MAPI} / \mathrm{mp}-\mathrm{Al}_{2} \mathrm{O}_{3} / \mathrm{c}-\mathrm{TiO}_{2} / \mathrm{FTO}$ stack, i.e., with a mesoporous $\mathrm{Al}_{2} \mathrm{O}_{3}$ layer but without a hole transport layer. It resembles closely the expected shape based on the simulations shown in Figure 11.

The red line depicts the EBIC scan of a planar device using Spiro-OMeTAD as a hole transport layer and compact $\mathrm{TiO}_{2}$ as an electron transport layer. In contrast to the EBIC profile in blue, this EBIC scan in red features a double-peak, which is not possible to be explained using any of the models shown in Figures $11 \mathrm{~b}$ and c. Future work will have to tell how to interpret the local minima appearing in the middle of the absorber layers seen in Figure 12b. 


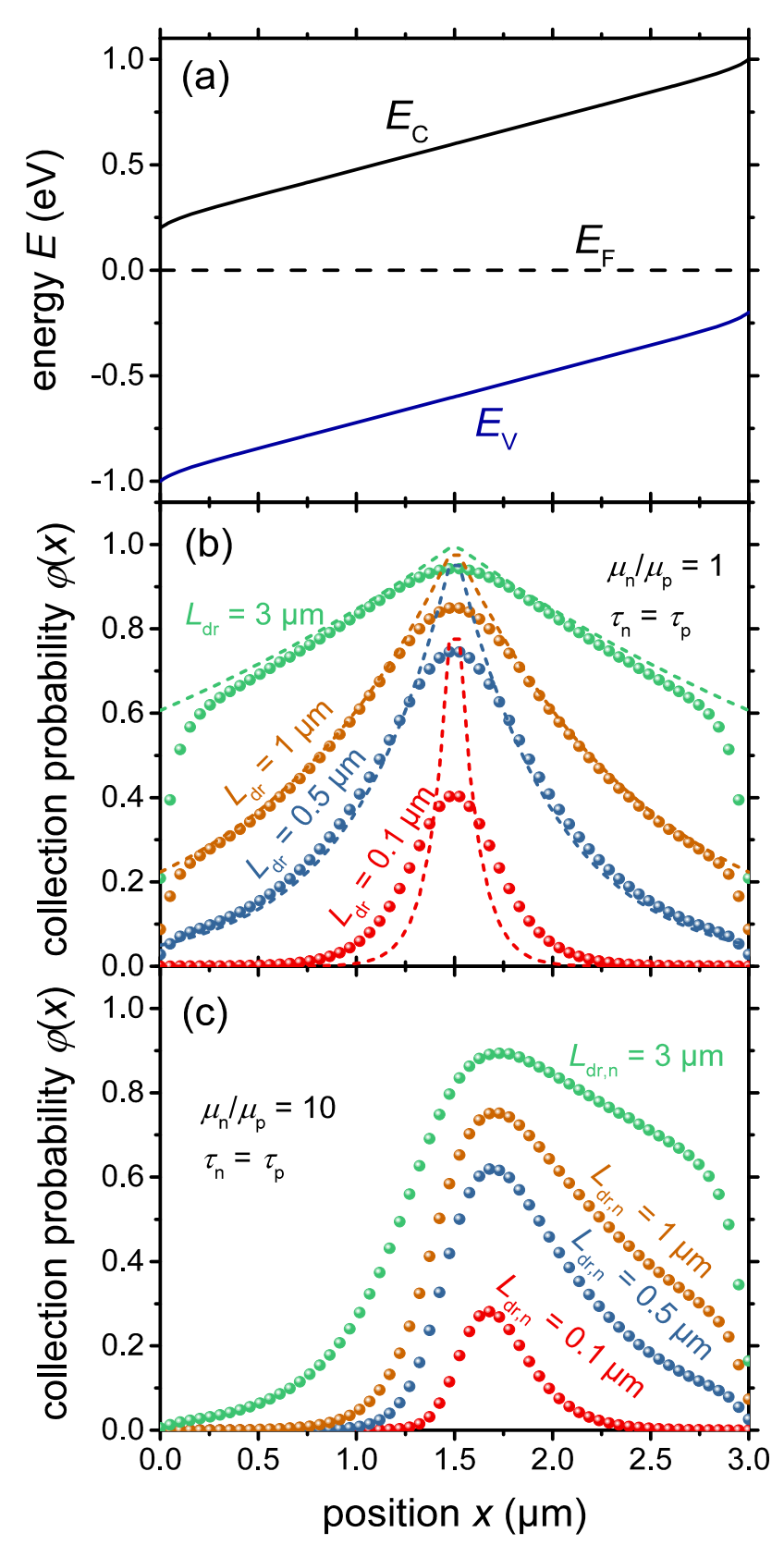

Figure 11: (a) Band diagram of a solar cell with $p-i-n$ junction. (b) Collection probability for different diffusion lengths of the $p$ - $i$ - $n$-type cell shown in (a) for different values of the drift length $L_{\mathrm{dr}}$ and perfectly symmetric mobilities and lifetimes for electrons and holes. (c) The same as in (b) but with mobilities that are asymmetric by a factor of 10 . Now, holes are collected less efficiently. Therefore, more current is collected if the electron-hole pair is generated closer to the hole contact (here on the right). In case of asymmetric mobilities or lifetimes, one carrier will limit charge collection, and thus, the peak collection efficiency is shifted towards the contact of the carrier type with the smaller drift length. 

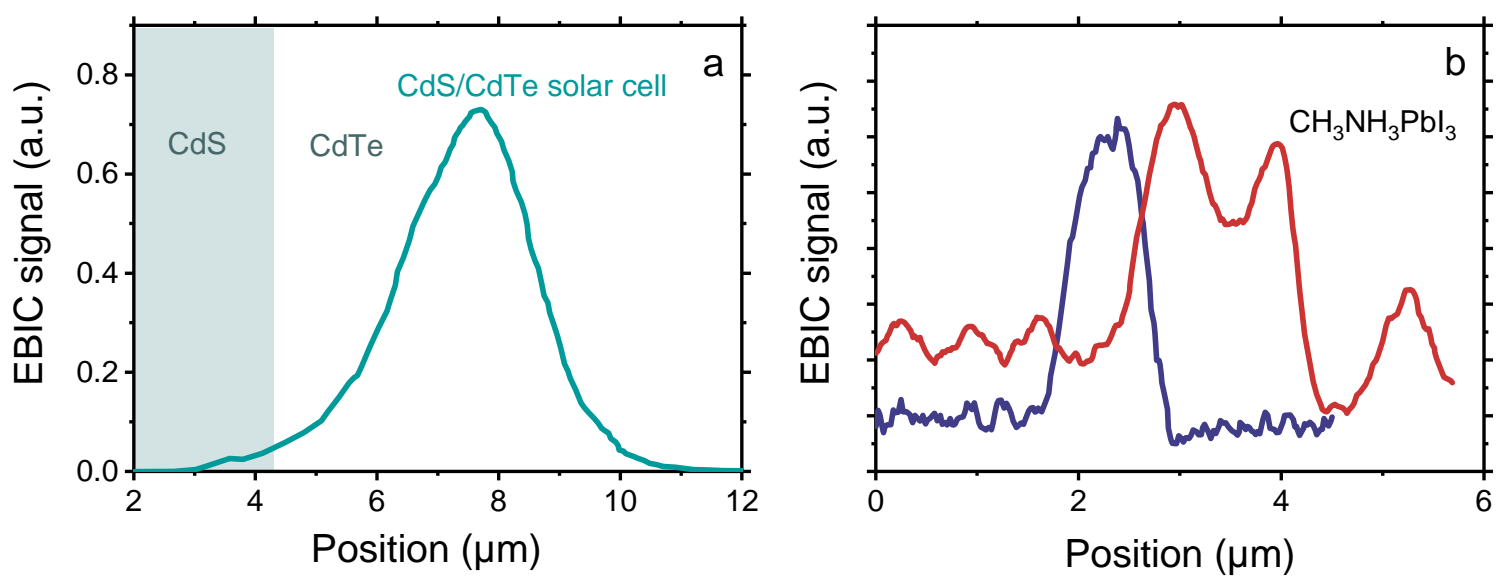

Figure 12: EBIC measurements of solar cells with absorber layers with low or even negligible doping concentrations that are in high level injection during an EBIC measurement. (a) shows data from a CdTe solar cell, extracted from Ref. ${ }^{35}$, which has a slightly asymmetric peak, quite similar to the simulations shown in Figure 11. (b) shows EBIC profiles acquired on lead-halide perovskite solar cells with different contact configurations (red: Au/Spiro-OMeTAD/MAPI/c$\mathrm{TiO}_{2} / \mathrm{FTO}$, blue: $\left.\mathrm{Au} / \mathrm{MAPI} / \mathrm{mp}-\mathrm{Al}_{2} \mathrm{O}_{3} / \mathrm{c}-\mathrm{TiO}_{2} / \mathrm{FTO}\right)$, extracted from Ref. ${ }^{36}$. The scan shown in red exhibits a double peak that cannot easily be explained in simulations. Note that the hole contact $(\mathrm{Au})$ is always on the left and the electron contact (FTO) on the right.

\section{EBIC signals across line and planar defects}

EBIC signals tend to be reduced at line (dislocations) or at planar defects (stacking faults, twins, random grain boundaries), owing to enhanced nonradiative recombination. Such a behavior is well known from multicrystalline or polycrystalline Si (e.g., Refs. ${ }^{37,38,39}$ ). By combining EBIC measurements with characterization by means of electron backscatter diffraction (EBSD) on the identical positions, it is possible to localize and categorize grain boundaries as well as study their influence on the collection behaviors (see, e.g., Refs. ${ }^{7,40,41}$ ). For example, these behaviors can be distinguished between random grain boundaries and highly symmetrical twin boundaries (i.e., those with a $\Sigma$ value of 3 ). As for stacking faults and dislocations within individual grains, it would be helpful to combine channeling-contrast imaging (see, e.g., Ref. ${ }^{42}$, and also Sec. 5.2. below on this matter), which can visualize these extended defects in the SEM image, with corresponding EBIC imaging on the identical positons (something that we have not yet done and has also not yet been reported).

In order to determine recombination velocities $s_{\mathrm{GB}}$ at grain boundaries (see Figure 2), a similar approach as the one described for surfaces (Sec. 3.3.) can be applied ${ }^{43}$. We consider the grainboundary plane an additional surface, at which the electron diffusion length is reduced, in addition to the recombination at the cross-section surface (see Figure 13). We also take into account that the grain-boundary plane is generally inclined at an angle $\alpha$ ( $\neq 0$ degrees) with respect to the cross-section surface. Let $y_{0}$ be the distance of the position of the impinging electron beam from the grain boundary. When calculating the reduced electron diffusion length using Eqs. 12-15, we can assume the average distance of generation sites from the inclined grain-boundary plane to be:

$$
\bar{y}=1 / R_{G} \int_{0}^{R_{\mathrm{G}}}\left|z / \tan (\alpha)-y_{0}\right| g(z) \mathrm{d} z .
$$




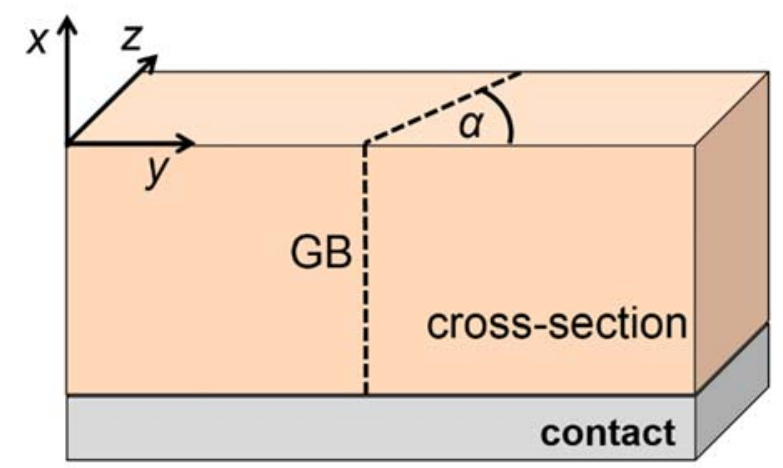

Figure 13: Schematics extracted from the one depicted in Figure 1, highlighting the $p$-type absorber layer with a grain boundary, of which, in the present case, the plane is oriented perpendicular to the substrate. Into the depth of the layer (i.e., in $z$ direction), the grain-boundary (GB) plane is inclined at an angle $\alpha$ with respect to the $y$ axis.

We now just need to use this average distance $\bar{y}$ instead of $z$ in the Eqs. 12-15, then insert the calculated electron diffusion length in Eq. 10, and finally convolute the collection probability with the generation profile (Eq. 2) in order to determine the EBIC value as a function of this average distance $\bar{y}$. Figure 14 shows an exemplary EBIC profile across a $\mathrm{CuInSe}_{2}$ grain boundary and the corresponding simulation obtained using the described procedure. In this case, the recombination velocity $s_{\mathrm{GB}}$ and the inclination angle $\alpha$ for the simulation were estimated to $5 \times 10^{3} \mathrm{~cm} / \mathrm{s}$ and 45 degrees.

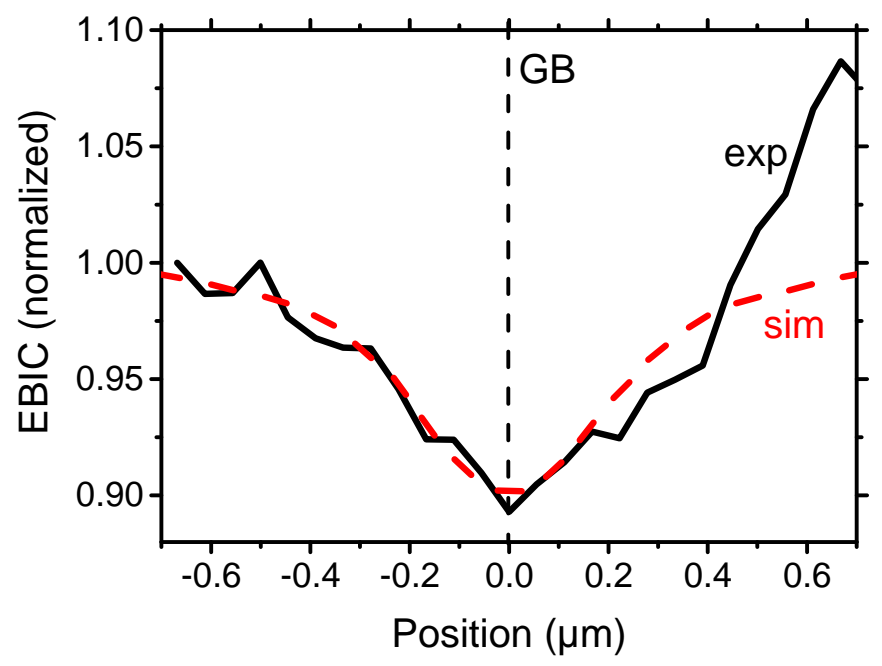

Figure 14: Experimental (exp) and simulated (sim) EBIC profiles across a $\mathrm{CuInSe} 2$ grain boundary (GB), extracted from the EBIC data published in Ref. ${ }^{41}$. The assumed $s$ GB value and the inclination angle for the simulation were $5 \times 10^{3} \mathrm{~cm} / \mathrm{s}$ and 45 degrees. The different EBIC levels in the two adjacent grains (normalized about 1 and 1.1) can be attributed to slightly different net-doping densities (see Refs. ${ }^{44,45,46,47}$, and also Sec. 5.4 below for further details on this matter).

\section{Pitfalls of EBIC analyses}

After dealing with the copious information which can be extracted from EBIC measurements, it is important also to address the limitations of this technique. We consider various issues in 
the following subsections which may affect the EBIC signals from polycrystalline thin-film solar cells substantially.

\subsection{Contacting}

To our experience, thin-film solar cells are best contacted for EBIC measurements in the same way as done for macroscopic, electrical analyses such as current-voltage, capacitance-voltage, or quantum efficiency measurements. When using nanoprobes in the electron microscope on, e.g., cross-sections, it is not clear whether the current goes through the solar-cell stack, or whether it only flows along the cross-section surface. It can also not be recommended to use pins made of a hard materials, since often, they tend to perforate the (brittle) thin-film stacks, leading to shunt faults and thus to very weak EBIC signals.

\subsection{Generation-dependent collection}

Up to now, we have assumed that Eq. 2 is always valid, i.e., that the generation profile $g(x-a)$ and the collection probability $\varphi(x)$ are two independent physical quantities, which are convoluted in order to obtain the EBIC value. However, transport properties in thin-film solar cells may be generation-dependent ${ }^{48}$, a property similar to the issue of illumination-dependent photocurrent collection reported for various solar-cell devices (see, e.g., Ref. ${ }^{49}$ ). In order to study this generation dependency, it is always advised to perform EBIC measurements at varying electron beam conditions (beam energy $E_{\mathrm{b}}$, beam current $I_{\mathrm{b}}$ ). This variation is also helpful in order to elucidate and quantify the influence of the cross-section surface on the local collection behavior of the charge carriers (see Sec. 3.2.3. above).

\subsection{Channeling contrast in EBIC images}

Channeling contrast imaging is a mechanism used in electron microscopy to visualize orientation distributions of polycrystalline materials as well as line and planar defects within individual grains or at grain boundaries ${ }^{42}$. This mechanism is based on the fact that if grains are oriented in such a way that the atomic columns are (nearly) parallel to the incident electron beam, i.e., the grain is oriented to a zone axis, the electrons penetrate much deeper into the material (channeling), and hence, the backscattered fraction of these electrons is much smaller than in cases for which such a special orientation is not given. As a consequence, such grains oriented to zone axes appear dark in the electron image (see Figure 15a for an example), and others bright.

For EBIC signals, this behavior is exactly inversed (see Figure 15b). If electrons can penetrate deeper into the material via channeling and thus the fraction of backscattered electrons is smaller, the EBIC signal becomes larger, because the probability for the generation of electronhole pairs by these electrons becomes higher. Therefore, the SEM and EBIC images in Figures $15 \mathrm{a}$ and $\mathrm{b}$, acquired on the identical area on $\mathrm{Cu}(\mathrm{In}, \mathrm{Ga}) \mathrm{Se}_{2} / \mathrm{CdS} / \mathrm{i}-\mathrm{ZnO} / \mathrm{ZnO}: \mathrm{Al}$ stack, exhibit inverse contrast distributions across the images. 

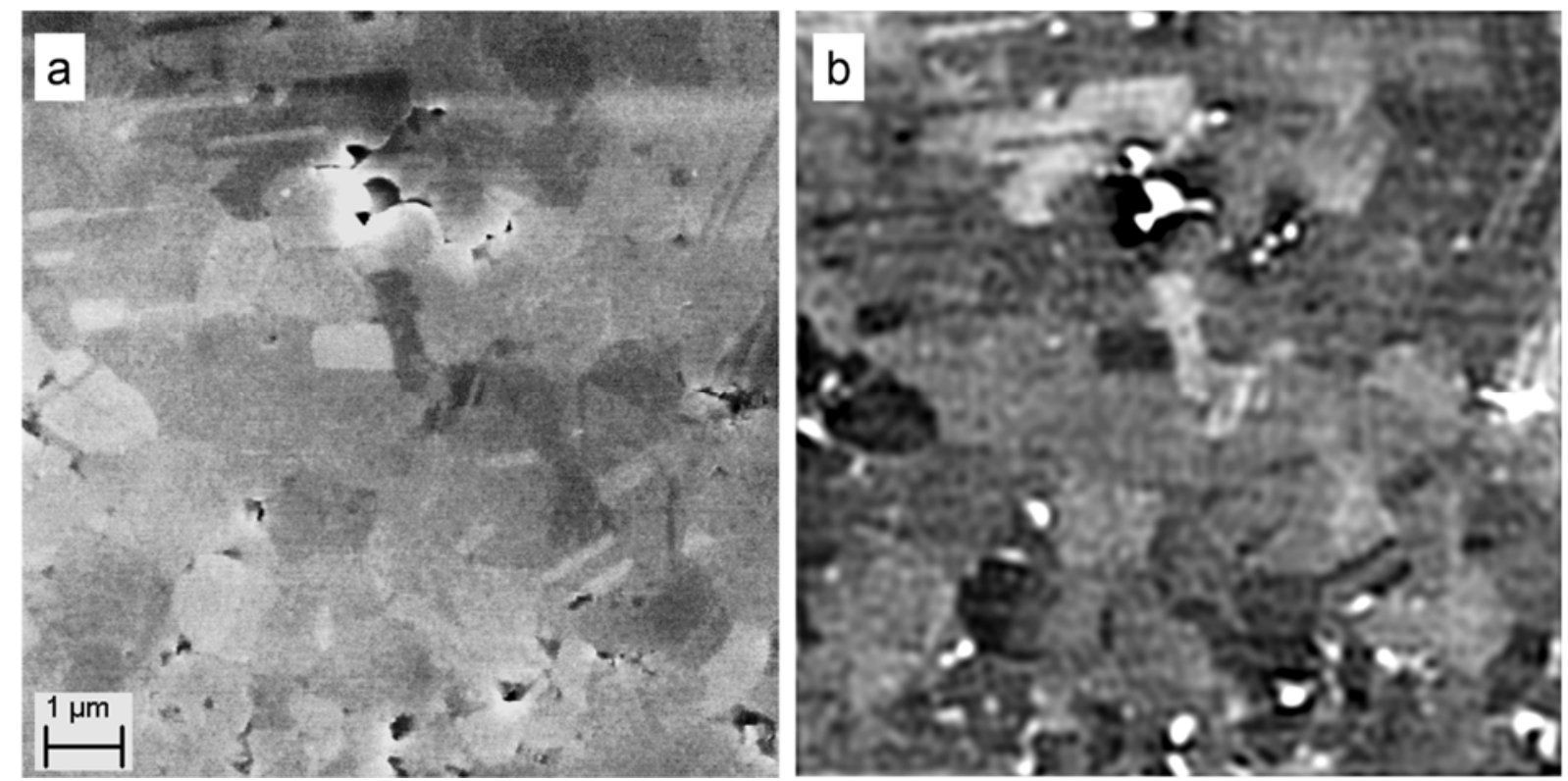

Figure 15: SEM (a) and EBIC images (b) acquired on the same identical position of a $\mathrm{Cu}(\mathrm{In}, \mathrm{Ga}) \mathrm{Se}_{2} / \mathrm{CdS} / \mathrm{i}-\mathrm{ZnO} / \mathrm{ZnO}: \mathrm{Al}$ stack (data by courtesy of $\mathrm{M}$. Nichterwitz, HZB). A channeling contrast in the SEM image visualizes individual grains; this contrast is inverted in the EBIC image.

5.4. Variation of the net-doping densities between neighboring grains and within individual grains

In a polycrystalline semiconductor thin film, it can be expected that point defects are not distributed homogeneously. Consequently, the net doping of this semiconductor layer needs not to be homogeneously distributed across the thin film. Evidence for this inhomogeneous distribution of the net-doping density has already been provided by several authors ${ }^{44,45,46,47}$ via analyses conducted via scanning spreading-resistance microscopy. Spatial changes in the net doping affect the transport properties and also introduce band bending via Poisson's equation, both having impact on the EBIC signal.

\subsection{High-injection conditions}

The approaches presented in Secs. 3 and 4 can only be applied when low-injection conditions are given, i.e., if the density of electron-hole pairs generated by the incident electron beam does not become larger than the net-doping density of the semiconductor. However, in an electron microscope with beam energies $E_{\mathrm{B}}$ of several $\mathrm{keV}$, this condition may not hold. Especially when using small $E_{\mathrm{B}}$ values of few $\mathrm{keV}$, great care is advised; in this case, the excitation volume remains very small, and when using too large beam currents $I_{\mathrm{B}}$, the density of generated electron-hole pairs may become very large. Then, high-injection and not low-injection conditions are obtained. For $p-i-n$ structures (Sec. 3.3.), high-injection conditions are often unavoidable.

The density of generated electrons or holes, $\Delta n_{n, p}$, is equal to $G \tau_{n, p}$, where $G$ the generation rate per $\mathrm{cm}^{3}$ and $\mathrm{s}$, and $\tau_{\mathrm{n}, \mathrm{p}}$ the lifetime of electrons or holes. $\mathrm{G}$ can be estimated roughly by dividing the generation rate of electron-hole pairs, $A$, from Eq. 3 by the excitation volume, approximated by a sphere with radius $R_{\mathrm{G}} / 2$ (i.e., the Green penetration depth from Sec. 3.2.1.). The resulting equation is ${ }^{50}$ 


$$
\Delta n_{n, p}=\frac{E_{\mathrm{b}}(\mathrm{keV}) I_{\mathrm{b}}}{e E_{\mathrm{eh}}}(1-\lambda)\left(\frac{4}{3} \pi\left(\frac{R_{\mathrm{G}}}{2}\right)^{3}\right)^{-1} \tau_{n, p} .
$$

The change from low-injection to high-injection conditions and the corresponding effects on

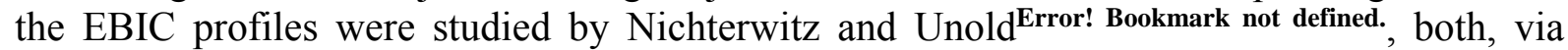
experimental and numerically simulated EBIC distributions. The results are depicted in Figure 16 for a $\mathrm{ZnO} / \mathrm{CdS} / \mathrm{CuInSe}_{2} / \mathrm{Mo}$ solar cell ( $p$ - $n$ junction) with a net-doping concentration in the $\mathrm{CuInSe} 2$ layer of $2 \times 10^{15} \mathrm{~cm}^{-3}$ and a beam energy of $E_{\mathrm{B}}=10 \mathrm{keV}$. It can be seen that the lateral distribution of the EBIC signal changes from a form typical for a $p-n$ junction with the local maximum close to the junction region (Sec. 3.2.) to one where the local maximum shifted towards the back contact, which can be described via a model for a $p-i-n$ junction (Sec. 3.3.). Since the excitation volume depends strongly on the Green penetration depth $R_{\mathrm{G}}(\mathrm{Eq} .15)$ and thus on the beam energy, low-injection conditions can be reached easiest by selecting high $E_{\mathrm{B}}$ and low $I_{\mathrm{B}}$. Beam energies $E_{\mathrm{B}}$ of lower than $8-10 \mathrm{keV}$ for EBIC measurements should be avoided, not only because of the smaller excitation volumes, but also because of the stronger influences by recombination at the cross-section surface.

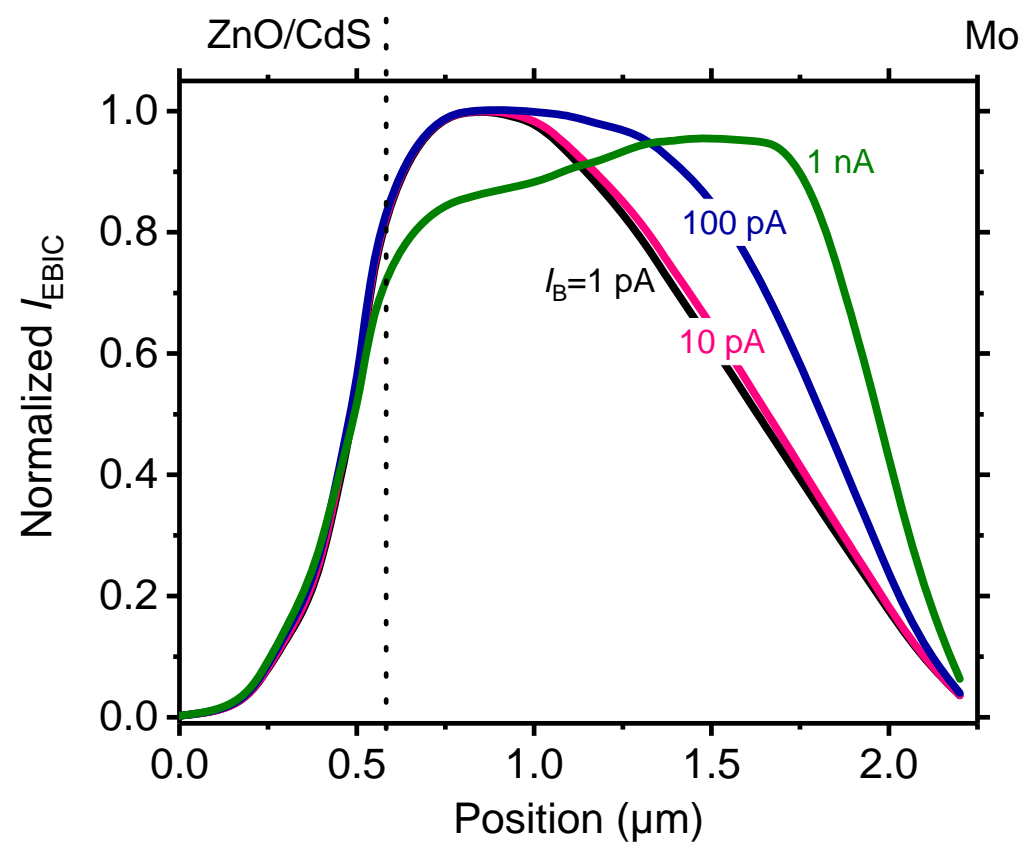

Figure 16: Numerically modeled EBIC profiles in a using a one-dimensional device simulator, showing the change in the distribution of the EBIC signal with varying beam energy $I_{\mathrm{B}}$. The simulations were performed assuming $E_{\mathrm{B}}=10 \mathrm{keV}$ and a net-doping concentration in the CuInSe 2 layer of $2 \times 10^{15} \mathrm{~cm}^{-3}$. Reproduced using the data from Ref. ${ }^{30}$.

\subsection{Enhanced EBIC signals at grain boundaries}

Enhanced EBIC signals at GBs as compared with those from grain interiors (see Figure 17 for examples) were reported by several authors, often interpreted in terms of superior electrical properties at GBs (e.g., Refs. ${ }^{51,52}$ ). If not owing to the topography of a fractured cross-section (as in Figure 4), enhanced EBIC signals at GBs (as compared with in grain interiors) can be attributed usually to high-injection conditions. Indeed, Galloway et al. ${ }^{53}$ reported about a 
change from local minima to local maxima in the EBIC signals at CdTe GBs when changing the beam current from $0.5 \mathrm{pA}$ to $1 \mathrm{nA}$, i.e., probably changing from low-injection to highinjection conditions for the low-doped CdTe (net-doping densities of about $10^{14} \mathrm{~cm}^{-3}$ ).

The effect of the injection condition on the ratio of EBIC signals at the GB and in the grain interior can be traced back to decreased recombination velocities for high-injection as compared with for low-injection conditions ${ }^{50,54}$. We may take a look at the dependency of the recombination velocity as a function of the interface charge density, $N_{\mathrm{it}}$, and the barrier height $\Phi_{\mathrm{b}}$ for charge carriers at the grain-boundary plane (the barrier results from redistribution of free charge carriers around the charged GB plane, leading to band bending via Poisson's equation $)^{55}$ :

$$
s_{\mathrm{GB}}=1 / 4 N_{\text {it }} v_{\text {th }} \sigma_{\mathrm{n}} \exp \left(\Phi_{\mathrm{b}} / k_{\mathrm{B}} T\right),
$$

where $v_{\text {th }}=1 \times 10^{7} \mathrm{~cm} / \mathrm{s}$ is the thermal velocity of the charge carriers, and $\sigma_{\mathrm{e}}$ is the capture crosssection for electrons ( $e$ is the elemental charge, $k_{\mathrm{B}}$ the Boltzmann constant, $T$ the absolute temperature). With typical values of $\Phi_{\mathrm{b}}=50-100 \mathrm{meV}$ (orders of magnitude) for net-doping densities of $10^{15}-10^{16} \mathrm{~cm}^{-3}$ (see Ref. ${ }^{56}$ for more details on how the barrier height depends on the doping density) as used in $\mathrm{Si}, \mathrm{CdTe}$, or $\mathrm{Cu}(\mathrm{In}, \mathrm{Ga}) \mathrm{Se}_{2}$ for high-efficiency solar cells, $N_{\mathrm{it}} \approx$ $10^{11} \mathrm{~cm}^{-2}$, and $\sigma_{\mathrm{n}} \approx 10^{-15} \mathrm{~cm}^{2}$, sGB takes average values of about $10^{3}-10^{4} \mathrm{~cm} / \mathrm{s}$, as determined also experimentally for both, $\mathrm{Si}$ and $\mathrm{Cu}(\mathrm{In}, \mathrm{Ga}) \mathrm{Se}_{2}$ solar cells ${ }^{41,57,58,59}$. We note that Eq. 16 describes the effective recombination velocity, which is increased by the band bending, driving charge carriers from the grain interiors to the GB.

While Eq. 16 is valid for low-injection conditions, the situation is different for high-injection conditions. This is because then, band bending and therefore barriers vanish at the GBs, owing to the fact that the electron and hole densities are the same everywhere. Eq. 16 changes to ${ }^{54} s \mathrm{~GB}$ $=1 / 4 N_{\mathrm{it}} v_{\mathrm{th}} \sigma_{\mathrm{p}}\left(\sigma_{\mathrm{p}}\right.$ is the capture cross-section for holes), and thus, $s_{\mathrm{GB}}$ can become substantially smaller than for low-injection conditions (depending on the magnitudes of $\sigma_{\mathrm{n}}$ and $\sigma_{\mathrm{p}}$ ). In addition, the recombination rate is maximum for equal electron and hole densities everywhere in the grain interiors. Thus, while the recombination rate becomes larger in the grain interiors when changing from low-injection to high-injection conditions, the situation may be exactly inverse for grain boundaries. Such a scenario may lead to enhanced EBIC signals at GBs (which does not mean that GBs exhibit better electrical properties than grain interiors, apparently).
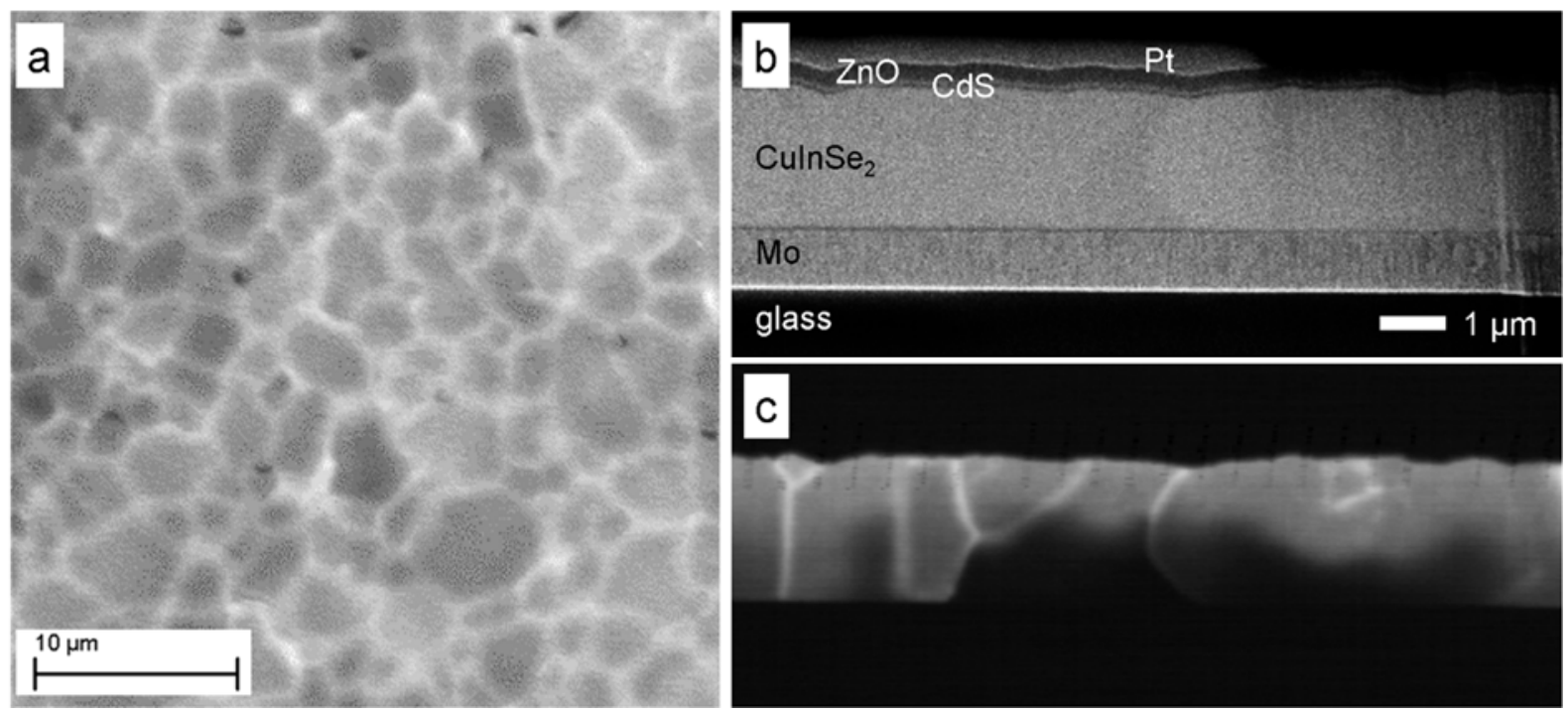

Figure 17: (a) EBIC image acquired at $10 \mathrm{keV}$ on a $\mathrm{Cu}(\mathrm{In}, \mathrm{Ga}) \mathrm{Se}_{2} / \mathrm{CdS} / \mathrm{i}-\mathrm{ZnO} / \mathrm{ZnO}: \mathrm{Al}$ stack, lifted off the Mo/glass substrate; the $\mathrm{Cu}(\mathrm{In}, \mathrm{Ga}) \mathrm{Se}_{2}$ was in contact with Ag epoxy glue, leading to $\mathrm{Ag}$ indiffusion into the $\mathrm{Cu}(\mathrm{In}, \mathrm{Ga}) \mathrm{Se}_{2}$ layer, assumingly decreasing the net-doping density in the absorber; grain boundaries exhibit enhanced EBIC signals as compared with the grain 
interiors (data by courtesy of M. Nichterwitz, HZB). (b) SEM and (c) EBIC images (5 keV, 100 $\mathrm{pA}$ ) of a cross-sectional specimen prepared from a $\mathrm{ZnO}: \mathrm{Al} / \mathrm{i}-\mathrm{ZnO} / \mathrm{CdS} / \mathrm{CuInSe} / \mathrm{Mo} /$ glass stack by means of a focused-ion beam instrument; again, grain boundaries exhibit enhanced EBIC signals as compared with the grain interiors; we note that other EBIC measurements (at higher beam energies) on the identical solar cell, prepared by lifting off the Mo/glass substrate, did not exhibit enhanced EBIC signals ${ }^{41}$ (data by courtesy of N. Schäfer, HZB).

\section{Conclusions}

EBIC can provide valuable insight into electrical properties of materials and junctions in thinfilm solar-cell devices. Especially when combined with imaging as well as structural and compositional analyses in a scanning electron microscope, it can be used to study microscopic structure-property relationships, which can be related to the macroscopic charge-carrier collection and thus to the device performance of the solar cell. In spite of the copious information that can be obtained when applying the EBIC technique, care is advised to observe the divers pitfalls that may be encountered when evaluating the corresponding results.

\section{Acknowledgments}

D.A. is grateful for financial support by the Helmholtz Virtual Institute "Microstructure Control for Thin-Film Solar Cells" (VH-VI-520), by the Helmholtz International Research School HISCORE (HIRS-0008) and by the BMWi project EFFCIS (No. 0324076B). T.K. acknowledges financial support from the BMWi via the project CIGSTheoMax and support from the Helmholtz association via the project PEROSEED, as well as Paula Hartnagel, Univ. DuisburgEssen, for help with the digitalization of the data in Fig. 12. Special thanks are due to Prof. David Cahen, Bar-Ilan University and Weizmann Institute of Science, for motivating the authors to write the present EBIC tutorial. 
For Table of Contents Only :

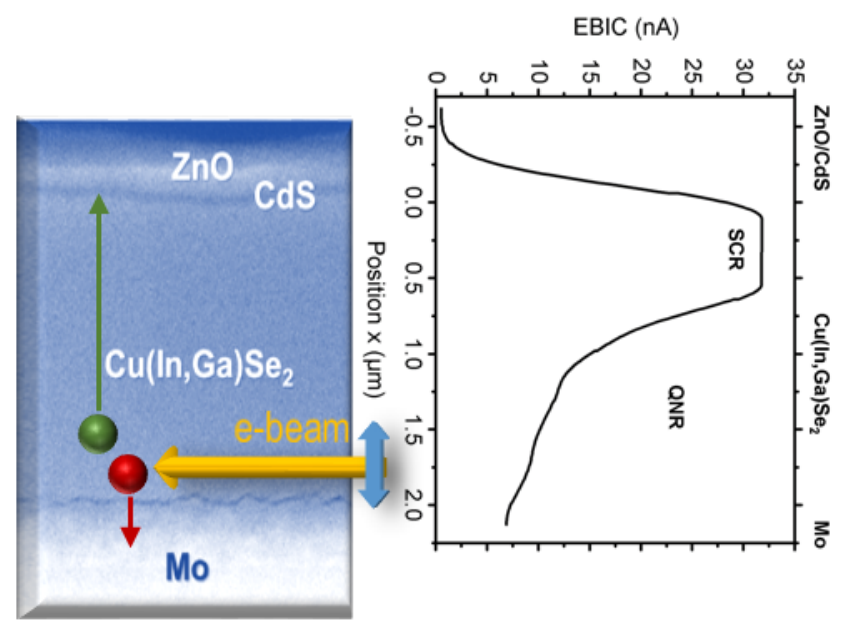


${ }^{1}$ Ehrenberg, W.; Lang, C.-S.; West, R. The electron voltaic effect. Proceedings of the Physical Society. Section A 1951, 64, 424.

${ }^{2}$ Rappaport, P. The electron-voltaic effect in p-n junctions induced by beta-particle bombardment. Physical Review 1954, 93, 246.

${ }^{3}$ Everhart, T. E.; Wells, O. C.; Matta, R. K. A novel method of semiconductor device measurements. Proceedings of the IEEE 1964, 52, 1642-1647.

${ }^{4}$ Holt, D.B. The conductive mode, in: SEM Microcharacterization of Semiconductors, D.B Holt, D.C. Joy (Eds.), ch. 6, p. 241 (Academic Press Inc., San Diego, 1989).

${ }^{5}$ Leamy, H. J. Charge collection scanning electron microscopy. J. Appl. Phys. 1982, 53, R51R80.

${ }^{6}$ Scheer, R. Qualitative and quantitative analysis of thin film heterostructures by electron beam induced current. Solid State Phen. 1999, 67, 57-68.

${ }^{7}$ Kavalakkatt, J.; Abou-Ras, D.; Haarstrich, J.; Ronning, C.; Nichterwitz, M.; Caballero, R.; Schock, H. W. Electron-beam-induced current at absorber back surfaces of $\mathrm{Cu}$ (In, Ga) $\mathrm{Se} 2$ thin-film solar cells. J. Appl. Phys. 2014, 115, 014504.

${ }^{8}$ Donolato, C. An alternative proof of the generalized reciprocity theorem for charge collection. Journal of Applied Physics 1989, 66, 4524-4525.

${ }^{9}$ Abou-Ras, D.; Schäfer N.; Baldaz N.; Brunken S., Boit, C. Electron-beam-induced current measurements with applied bias provide insight to locally resolved acceptor concentrations at $p$ - $n$ junctions. AIP Adv. 2015, 5, 077191.

${ }^{10}$ Shea, S. P., Partain, L. D., \& Warter, P. J. (1978). Resolution limits of the EBIC technique in the determination of diffusion lengths in semiconductors. Scanning Electron Microscopy, $1,435-444$.

${ }^{11}$ Rechid, J.; Kampmann, A.; Reineke-Koch, R. Characterising superstrate CIS solar cells with electron beam induced current. Thin Solid Films 2000, 361, 198-202.

${ }^{12}$ Pieters, B.E.; Decock, K.; Burgelman, M.; Stangl, R.; Kirchartz T. One-Dimensional Electro-Optical Simulations of Thin-Film Solar Cells, in: Advanced Characterization Techniques for Thin Film Solar Cells, Edited by D. Abou-Ras, T. Kirchartz, and U. Rau (Wiley-VCH, 2011), p. 501.

${ }^{13}$ Pieters, B.E.; Krc, J.; Zeman, M.. Advanced Numerical Simulation Tool for Solar Cells ASA5. Conference Record of the 2006 IEEE 4th World Conference on Photovoltaic Energy Conversion, (IEEE, New York, 2006), p. 1513.

${ }^{14}$ Brendel, R.; Rau, U. Effective diffusion lengths for minority carriers in solar cells as determined from internal quantum efficiency analysis. J. Appl. Phys. 1999, 85, 3634.

${ }^{15}$ Rau, U.; Brendel, R. The detailed balance principle and the reciprocity theorem between photocarrier collection and dark carrier distribution in solar cells J. Appl. Phys. 1998, 84, 6412.

${ }^{16}$ Donolato, C. A reciprocity theorem for charge collection Appl. Phys. Lett. 1985, 46, 270.

${ }^{17}$ Misiakos, K.; Lindholm, F. A. Generalized reciprocity theorem for semiconductor devices. J. Appl. Phys. 1985, 58, 4743.

${ }^{18}$ Green, M.A. Generalized relationship between dark carrier distribution and photocarrier collection in solar cells. J. Appl. Phys. 1997, 81, 268.

${ }^{19}$ Markvart, T. Relationship between dark carrier distribution and photogenerated carrier collection in solar cells IEEE Trans. Elec. Dev. 1996, 43, 1034.

${ }^{20}$ Rau, U. Reciprocity relation between photovoltaic quantum efficiency and electroluminescent emission of solar cells Phys. Rev. B 2007, 76, 085303.

${ }^{21}$ Rau, U. Superposition and reciprocity in the electroluminescence and photoluminescence of solar cells. IEEE J. Photovolt. 2012, 2, 169. 
${ }^{22}$ Sze, S. M.; Ng, K.K. Physics of semiconductor devices (John Wiley \& Sons, 2006).

${ }^{23}$ Krause, M.; Nikolaeva, A.; Maiberg, M.; Jackson, P.; Hariskos, D.; Witte, W.; Márquez, J.A.; Levcenko, S.; Unold, T.; Scheer, R.; Abou-Ras, D. Microscopic analysis of a highefficiency $\mathrm{Cu}(\mathrm{In}, \mathrm{Ga}) \mathrm{Se} 2$ solar cell - a case study, unpublished.

${ }^{24}$ Hages, C.J.; Redinger, A.; Levcenko, S.; Hempel, H.; Koeper, M. J.; Agrawal, R.; Greiner, D.; Kaufmann, C.A.; Unold, T. Identifying the real minority carrier lifetime in nonideal semiconductors: A case study of kesterite materials. Adv. En. Mater. 2017, 7, 1700167. ${ }^{25}$ X. X. Liu and J. R. Sites, Solar-cell collection efficiency and its variation with voltage. $J$. Appl. Phys. 1994, 75, 577.

${ }^{26}$ Jastrzebski, L.; Lagowski, J.; Gatos, H.C. Application of scanning electron microscopy to determination of surface recombination velocity: GaAs. Appl. Phys. Lett. 1975, 27, 537-539.

${ }^{27}$ Donolato, C. Evaluation of diffusion lengths and surface recombination velocities from electron beam induced current scans. App. Phys. Lett. 1983, 43, 120-122.

${ }^{28}$ Kniese, R., Ladungstransport in $\mathrm{Cu}(\mathrm{In}, \mathrm{Ga}) \mathrm{Se}_{2}$-Solarzellen mit unterschiedlichen Bandlückenenergien, Dissertation, KIT, Karlsruhe, Germany, November 2005, https://publikationen.bibliothek.kit.edu/1000005018/2764 (German).

${ }^{29}$ Hoff, P.H.; Everhart, T.E. Determination of kilovolt electron energy dissipation vs penetration distance in solid materials. J. Appl. Phys. 1971, 42, 5837-5846.

${ }^{30}$ Nichterwitz, M.; Unold, T. Numerical simulation of cross section electron-beam induced current in thin-film solar-cells for low and high injection conditions. J. Appl. Phys. 2013, 114, 134504.

${ }^{31}$ Crandall, R.S. Modeling of thin-film solar cells: Nonuniform field. J. Appl. Phys. 1984, 55, 4418.

${ }^{32}$ Crandall, R.S. Modeling of thin film solar cells: Uniform field approximation. J. Appl. Phys. 1983, 54, 7176.

${ }^{33}$ Crandall, R.S. Transport in hydrogenated amorphous silicon p-i-n solar cells. J. Appl. Phys. 1982, 53, 3350 .

${ }^{34}$ Kirchartz, T.; Agostinelli, T.; Campoy-Quiles, M.; Gong, W.; Nelson, J. Understanding the Thickness-Dependent Performance of Organic Bulk Heterojunction Solar Cells: The Influence of Mobility, Lifetime and Space Charge. J. Phys. Chem. Lett. 2012, 3, 3470 (2012).

${ }^{35}$ Yamaguchi, K.; Nakayama, N.; Matsumoto, H.; Ikegami, S. CdS-CdTe solar cell prepared by vapor phase epitaxy Jpn. J. Appl. Phys. 1977, 16, 1203.

${ }^{36}$ Edri, E.; Kirmayer, S.; Mukhopadhyay, S.; Gartsman, K.; Hodes, G.; Cahen, D. Elucidating the charge carrier separation and working mechanism of $\mathrm{CH}_{3} \mathrm{NH}_{3} \mathrm{PbI}_{3-\mathrm{x}} \mathrm{Cl}_{\mathrm{x}}$ perovskite solar cells, Nature Comm. 2014, 5, 3461.

${ }^{37}$ Kittler, M.; Seifert, W.; Higgs, V. Recombination Activity of Misfit Dislocations in Silicon, phys. stat. sol. (a) 1993, 137, 327.

${ }^{38}$ Chen, J.; Sekiguchi, T.; Xie, R.; Ahmet, P.; Chikyo, T.; Yang, D.; Ito, S.; Yin, F. Electronbeam-induced current study of small-angle grain boundaries in multicrystalline silicon.

Scripta Mater. 2005, 52, 1211-1215.

${ }^{39}$ Seifert, W.; Amkreutz, D.; Arguirov, T.; Krause, H. M.;Schmidt, M. Analysis of electronbeam crystallized large grained Si films on glass substrate by EBIC, EBSD and PL. Solid State Phenomena 2011, 178, 116-121.

${ }^{40}$ Nichterwitz, M.; Abou-Ras, D.; Sakurai, K.; Bundesmann, J.; Unold, T.; Scheer, R.; Schock, H. W. Influence of grain boundaries on current collection in $\mathrm{Cu}(\mathrm{In}, \mathrm{Ga}) \mathrm{Se}_{2}$ thin-film solar cells. Thin Solid Films 2009, 517, 2554-2557.

${ }^{41}$ Abou-Ras, D.; Schäfer, N.; Rissom, T.; Kelly, M. N.; Haarstrich, J.; Ronning, C.; Rollett, A.D. Grain-boundary character distribution and correlations with electrical and optoelectronic properties of CuInSe 2 thin films. Acta Mater. 2016, 118, 244-252. 
${ }^{42}$ Zaefferer, S.; Elhami, N.N. Theory and application of electron channelling contrast imaging under controlled diffraction conditions. Acta Mater. 2014, 75, 20-50.

${ }^{43}$ Nichterwitz, M. Korrelation von Mikrostruktur und elektrischen Eigenschaften von $\mathrm{Cu}(\mathrm{In}, \mathrm{Ga}) \mathrm{Se}_{2}$ Absorberschichten in Dünnschichtsolarzellen. Diploma Thesis, FU Berlin, 2008 (German).

${ }^{44}$ Kawamura, M.; Yamada, T.; Suyama, N.; Yamada, A.; Konagai, M. Grain boundary evaluation of $\mathrm{Cu}\left(\operatorname{In}_{1-\mathrm{x}} \mathrm{Ga}_{\mathrm{x}}\right) \mathrm{Se}_{2}$ solar cells. Jpn. J. Appl. Phys. 2010, 49, 062301.

${ }^{45}$ Oonishi, S.; Kawamura, M.; Takano, N.; Hashimoto, D.; Yamada, A.; Konagai, M. Characterization of $\mathrm{Cu}(\mathrm{In}, \mathrm{Ga}) \mathrm{Se}_{2}$ grain boundary properties by electron-and tip-probe methods. Thin Solid Films 2011, 519, 7347-7350.

${ }^{46}$ Jiang, C. S.; To, B.; Glynn, S.; Mahabaduge, H.; Barnes, T.; Al-Jassim, M.M. Recent progress in nanoelectrical characterizations of $\mathrm{CdTe}$ and $\mathrm{Cu}(\mathrm{In}, \mathrm{Ga}) \mathrm{Se}_{2}$. Conference Records of the 43rd IEEE Photovoltaic Specialists Conference (PVSC), 2016, pp. 3675-3680.

${ }^{47}$ Nishimura, T.; Sugiura, H.; Nakada, K.; Yamada, A. Accurate control and characterization of $\mathrm{Cu}$ depletion layer for highly efficient $\mathrm{Cu}(\mathrm{In}, \mathrm{Ga}) \mathrm{Se}_{2}$ solar cells. Progress in Photovoltaics: Research and Applications 2019, 27, 171-178.

${ }^{48}$ Nichterwitz, M.; Caballero, R.; Kaufmann, C. A.; Schock, H. W.; Unold, T. Generationdependent charge carrier transport in $\mathrm{Cu}(\mathrm{In}, \mathrm{Ga}) \mathrm{Se} 2 / \mathrm{CdS} / \mathrm{ZnO}$ thin-film solar-cells. J. Appl. Phys. 2013, 113, 044515.

${ }^{49}$ Walter, T.; Menner, R.; Köble, C.; Schock, H. W. Characterization and junction performance of highly efficient $\mathrm{ZnO} / \mathrm{CdS} / \mathrm{CuInS}_{2}$ thin film solar cells. Proceedings of the 12th European Photovoltaic Solar Energy Conference, 1994, p. 1755.

${ }^{50}$ Maurice, J. L.; Marfaing, Y. Theoretical study of high injection effects in EBIC measurements of grain boundary recombination velocity in silicon. Le Journal de Physique IV 1991, 1 , C6-77.

${ }^{51}$ Yoon, H. P.; Haney, P. M.; Ruzmetov, D.; Xu, H.; Leite, M. S.; Hamadani, B. H.; Talin, A.A.; Zhitenev, N. B. Local electrical characterization of cadmium telluride solar cells using low-energy electron beam. Sol. En. Mater. Sol. Cells 2013, 117, 499-504.

${ }^{52}$ Major, J. D. Grain boundaries in CdTe thin film solar cells: a review. Semicond. Sci. Techn. 2016, 31, 093001.

${ }^{53}$ Galloway, S. A.; Edwards, P. R.; Durose, K. Characterisation of thin film CdS/CdTe solar cells using electron and optical beam induced current. Solar Energy Materials and Solar Cells 1999, 57, 61-74.

${ }^{54}$ Brendel, R. Thin-film crystalline silicon solar cells: physics and technology. John Wiley \& Sons, 2003.

${ }^{55}$ Seager, C. H. Grain boundary recombination: Theory and experiment in silicon. J. Appl. Phys. 1982, 52, 3960-3968.

${ }^{56}$ Seto, J.Y. The electrical properties of polycrystalline silicon films. J. Appl. Phys. 1975, 46, 5247-5254.

${ }^{57}$ Abou-Ras, D., Nikolaeva, A.; Caicedo Dávila, S.; Krause, M.; Guthrey, H.; Al-Jassim, M.; Morawski, M.; Scheer, R. No Evidence for Passivation Effects of $\mathrm{Na}$ and $\mathrm{K}$ at Grain Boundaries in Polycrystalline $\mathrm{Cu}(\mathrm{In}, \mathrm{Ga}) \mathrm{Se}_{2}$ Thin Films for Solar Cells. To be published in Sol. RRL 2019. doi:10.1002/solr.201900095

${ }^{58}$ Hess, U.; Pichon, P.Y.; Seren, S.; Schönecker, A.; Hahn, G. Crystal defects and their impact on ribbon growth on substrate (RGS) silicon solar cells, Sol. En. Mater. Sol. Cells 2013, 117, 471-475.

${ }^{59}$ Trinh, C.T.; Bokalič, M.; Preissler, N.; Trahms, M.; Abou-Ras, D.; Schlatmann, R.; Amkreutz D.; Topič, M. Assessment of Bulk and Interface Quality for Liquid Phase Crystallized Silicon on Glass, IEEE J. Photovolt. 2019, 9, 364-373. 